\title{
EL RITMO DEL LENGUAJE: CONCEPTOS Y TÉRMINOS
}

\section{RHYTHM IN LANGUAGE: CONCEPTS AND TERMINOLOGY}

\author{
Jesús LuQue MoReno \\ Universidad de Granada
}

\begin{abstract}
Resumen: En este trabajo se analiza el concepto de ritmo en un sentido amplio teniendo en cuenta la multiplicidad de sentidos del término, así como otras denominaciones equivalentes o afines utilizadas a lo largo de la historia. El ritmo de lenguaje y el ritmo del verso en concreto son estudiados considerando tres factores fundamentales: la organización temporal, la organización prosódica y la organización propiamente rítmico-métrica. No cabe duda del carácter convencional del ritmo poético artístico y de sus paralelismos con las artes musicales.
\end{abstract}

Palabras clave: ritmo, lenguaje, metro, organización temporal, organización prosódica.

\begin{abstract}
The concept of rhythm is analyzed in a general sense, while considering the various meanings of the term and other equivalent and similar words used historically. Language rhythm and particularly verse rhythm are studied from three fundamental perspectives: temporal, prosodic and metrical organization. There is no doubt about the conventional character of artistic poetic rhythm and its parallelism with the musical arts.
\end{abstract}


Key words: rhythm, language, meter, temporal organization, prosodic organization. 


\section{El ritmo}

7 L ritmo, algo no exclusivo de la música o del lenguaje, sino connatural a todo proceso sonoro, motriz o temporal, ha sido siempre un concepto bastante problemático, en modo alguno fácil de encerrar dentro de los límites de una definición. ${ }^{1}$ Los términos con que se lo designa resultan a veces ambiguos y son objeto de empleos no siempre adecuados, hasta el punto de que incluso en diccionarios y en escritos técnicos se deja a veces sentir esta indefinición ${ }^{2}$.

El término "ritmo", además, se aplica no sólo a una serie de sucesos sonoros, sino visuales (el ritmo de una señal luminosa o de una sucesión de colores); se habla igualmente de ritmo dentro de procesos naturales como las cuatro estaciones del año, al igual que se habla del ritmo de la vida; se habla incluso de ritmo con referencia no ya a procesos temporales sino a fenómenos más bien espaciales: el ritmo de una fachada, o de un grupo escultórico o de un cuadro.

"Is (rhythm) -escribía De Groot ${ }^{3}$ - frequently used for any kind of repetition or periodicity in the physical world, also for any kind of correspondence in asthetic experience, and, generally, for practically anything connected with experience as long as it is not clearly defined".

Ya Aristides Quintiliano dejaba constancia expresa de esta multiplicidad de sentidos del término griego ṕӨ además el fenómeno en relación con sucesos no sólo audibles,

\footnotetext{
${ }^{1} \mathrm{El}$ presente trabajo ha sido realizado en el seno del proyecto de investigación FFI 2008-05611/FILO. El prof. Pedro Pablo Fuentes, de la Universidad de Granada, tuvo a bien leer y corregir el original.

${ }^{2} C f$., por ejemplo, Waltz 1948, pp. 109 ss.

3 1968, p. 541 .
} 
sino también visibles y tangibles, como, respectivamente, los movimientos de la danza o el pulso de las arterias ${ }^{4}$ :

La palabra ritmo se usa en tres sentidos: se dice de los cuerpos inmóviles (como cuando hablamos de una estatua eurrítmica), de todos los móviles (y así decimos que alguien camina eurítmicamente) y, en un sentido específico, de la voz. Acerca de este último nos proponemos hablar ahora.

El ritmo es, en efecto, un sistema formado a partir de tiempos dispuestos con algún orden, a cuyos estados llamamos ársis y thesis, ruido y reposo (...).

Todo ritmo se percibe por estos tres sentidos: por la vista, como la danza; por el oído, como el mélos; o por el tacto, como en las pulsaciones de las arterias. Pero el ritmo musical se percibe por dos, la vista y el oído. En música son regulados rítmicamente el movimiento del cuerpo, la melodía y la dicción. Cada uno de ellos se observa tanto en sí mismo como junto a los demás, específicamente con uno u otro o con ambos a la vez .

Aquí una posible cuestión previa sería la de si es o no natural la discontinuidad de los procesos en cuanto se toman como temporales. Cabría en esto la misma doble postura posible en los procesos físicos, susceptibles de ser concebidos bien como un todo unitario en el que las partículas se imponen sólo como hipótesis necesaria o bien como una sucesión de entes o corpúsculos o momentos independientes. Lo mismo ocurre con una melodía, con el galope de un caballo, con el movimiento de los astros o con los múltiplos o las potencias de un número. Hay además en todo esto el problema añadido del concepto de "natural": de si lo que percibimos o interpretamos en estos procesos es así independientemente de que lo percibamos así. Cabría incluso reconcer con García Calvo ${ }^{6}$ que la noción de "rítmico" es más clara que la de "natural".

Definido el ritmo como "ordenación de los tiempos" ( $\tau$ ákı $1 \zeta$ $\chi \rho o ́ v \omega v)$ por Aristóxeno de Tarento, el músico discípulo de Aristóteles, dicha concepción ha sido luego sucesivamente reelaborada, pero no radicalmente cambiada, ni siquiera por los que en época moderna se han ocupado de la cuestión desde campos diversos, como la lingüística, la música o la psicología.

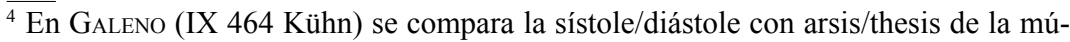
sica.

${ }^{5}$ De mus. I 13, p. 31 W.-I. Trad. L. Colomer y B. Gil, Madrid, 1996.

${ }^{6} 1979$, p. 249 ss. 
Las definiciones modernas tanto del ritmo en general, como del ritmo del lenguaje en particular, insisten en el factor motriz o temporal:

All rhythm, it seems likely, is ultimately rhythm of bodily movement (...) The rhythm of speech, therefore, is primarily muscular rhythm, a rhythm of bodily movement, rather than a rhythm of sound ${ }^{7}$.

A su vez, este movimiento regularizado se asocia en muchos contextos no lingüísticos con una regularidad temporal más o menos estricta ${ }^{8}$. Y como resultado de todo ello, el ritmo termina identificándose con patrones de intervalos entre movimientos o entre comienzos o cumbres, o con patrones de duración de los movimientos, antes que con los patrones cualitativos de dichos movimientos. Warren ${ }^{9}$, por ejemplo, definía el ritmo en estos términos:

The serial recurrence of a given time interval or group of time intervals, marked of by sounds, organics movements, etc.

Y Sonnenschein ${ }^{10}$ :

that property of a sequence of events in time which produces on the mind of the observer the impression of proportion between the durations of the several events or groups of events of which the sequence is composed.

Luego, como música y lenguaje tienen en común el operar con el sonido, esta concepción cuantitativa del ritmo se transfiere con frecuencia desde el contexto de la música al de la poesía $y$ al de la lengua en general, hasta el punto de que con frecuencia se ha considerado la duración como el factor primario del ritmo. Bien es verdad que también se han alzado voces proclamando la insuficiencia de esta concepción temporal y duracional y la necesidad de hacer intervenir otro factor de prominencia, generalmente de tipo intensivo ${ }^{11}$.

\footnotetext{
${ }^{7}$ ABercrombie 1965, pp. 7 y 19, respectivamente. En la misma línea, $c f$. Goodell 1901, pp. 91 s.; De Groot 1930, p. 227 o Fry 1958, p. 129; 1964, p. 217, todos ellos mencionados por AlLEN 1973, p. 97.

${ }^{8}$ Por ejemplo, en los ritmos de la naturaleza, en los del pulso, en la respiración o en el caminar; otro tanto ocurre en la música y en la danza.

${ }^{9} 1934$, s.v.

${ }^{10} 1925$, p. 16.

${ }^{11}$ Sobre todo esto, $c f$. AlLen 1973, p. 97 y LuQue 1994, pp. 38 ss.
} 
La idea del ritmo como algo fundamentalmente motriz no es cosa de tiempos modernos; está en la base de la formulación aristoxénica que terminó imponiéndose en la Antigüedad. Aun así, parece que ni el concepto de ritmo ni siquiera el término con el que lo designaron los griegos tuvieron desde un principio una vinculación directa y primaria con el movimiento y con el tiempo.

Así las cosas, tanto en lo que atañe al ritmo en general como, y sobre todo, en lo que se refiere al ritmo del lenguaje, se mantienen con plena vigencia cuestiones como su naturaleza objetiva o subjetiva o la importancia que en él hay que reconocerles a los factores temporales y no temporales ${ }^{12}$, o cuestiones como la isocronía o anisocronía de los intervalos o patrones rítmicos ${ }^{13}$ o como la distinción entre ritmo "primario" y "secundario" o como la determinación de los factores que pueden intervenir o que de hecho intervienen en el ritmo del lenguaje, es decir, los elementos lingüísticos que se muestran con mayor capacidad para constituirse en base de ritmo ${ }^{14}$ (las modulaciones tonales; las modulaciones de intensidad y sus relación con las tonales o con factores motrices) o como la cuestión del ictus y con ella

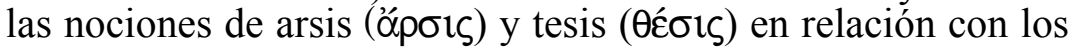
tiempos del flujo rítmico ${ }^{15}$.

\section{El ritmo del lenguaje: la articulación del sonus vocis}

Ciñéndonos al terreno del lenguaje, es evidente que la realidad sonora del hecho físico de que se sirve como medio, es decir, la materia y la forma del significante tal y como se materializa en el acto del habla, es algo que ha de ser tenido en cuenta, al menos en sus líneas generales, por todo aquel que, como nosotros, pretenda aproximarse a la articulación rítmica de la producción oral de dicho sistema de signos ${ }^{16}$.

$\overline{{ }^{12} C} f$., por ejemplo, ALLEN 1973, pp. $97 \mathrm{~s}$.

${ }^{13} C f$. asimismo Allen 1973, p. 99. En lo que se refiere al ritmo de la lengua, la isocronía real, objetiva, del ritmo ha quedado hoy descartada experimentalmente por los estudios de los fonetistas.

${ }^{14} C f$. de nuevo Allen 1973, pp. 99 ss.

${ }^{15}$ Cf. LuQue 1994; 1995, pp. 115 ss.

${ }^{16}$ Yo voy a hacerlo aquí sumariamente, de la mano de un fonetista ya clásico, de absoluta solvencia, como es ABERCROMBIE (1967), y de la no menos sabia mano de LAVER, en cuyo tratado (1994) se recogen además aportaciones recientes en este 
La producción del habla es en sí un fenómeno complejo, que va desde las fases de iniciación (intervenvión de los músculos intercostales y diafragmáticos, los pulmones, etc.), fonación (la laringe, las cuerdas vocales) y articulación (rápida modificación de los órganos del tracto vocálico, los denominados "órganos de resonancia" para crear patrones fonéticos que funcionen como vocales, consonantes u otras entidades fonológicas), a las fases de organización temporal del habla (duración de los elementos individuales, velocidad general, continuidad de la cadena hablada), de organización prosódica (control del tono y de la intensidad) y organización rítmico-métrica (la organización de las unidades rítmicas superiores - las frases, las palabras-, que, a su vez, refleja la interacción rítmica de las sílabas y el "stress" o el "peso silábico") ${ }^{17}$.

La interacción de elementos y factores de cada uno de estos planos o aspectos de la producción del habla puede dar lugar a una serie de rasgos o componentes de dicha habla que constituyen variables independientes y que son relativamente controlables por el hablante; lo cual tiene una trascendental importancia en el acto del habla y no puede dejar de ser tenido en cuenta por quien pretenda analizarlo.

Todos estos factores, los registros sonoros de la fonación, los diversos tipos de fonación, la entidad articulatoria (timbre) de los sonidos vocales o consonantes, su entidad temporal (duración, 'tempo', continuidad) y prosódica (prominencia, tono, intensidad) y su organización rítmico-métrica, constituyen la base de la complejísima información que transmite el acto de habla; su riqueza semiótica es enorme. En efecto, el mensaje no se reduce a lo que podríamos denominar ${ }^{18}$ "información semántica" (la información normal del lenguaje en cuanto que sistema de signos), sino que conlleva también una "información sintomática o indicadora" ${ }^{19}$ de unas características personales del

terreno. Al lector deseoso de ampliar cualquiera de las interesantísimas cuestiones que yo aquí voy a esbozar lo remito a los escritos de dichos autores.

${ }^{17} C f$. al respecto, por ejemplo, AberCrombie 1967, pp. 1 ss.; Lehiste 1970, passim;

LAVER 1994, pp. 116 ss.

${ }^{18}$ Con Laver 1994, pp. 13 ss.

${ }^{19}$ Es lo que ABERCROMBIE denominó "index", considerándolo como algo propio del "medium" (a los rasgos del "medium" portadores de tales signos los denomi- 
hablante ${ }^{20}$ y una "información reguladora" 21 , que da a entender el deseo del hablante de proseguir o no en el uso de la palabra.

Bien es verdad que estos tres tipos de información no se canalizan exclusivamente a través de la voz del habla, sino que se sirven de otros medios no audibles, visuales, por ejemplo. De ahí que, en principio, se suele hablar de dos tipos de medios en la comunicación: los vocales, sonoros, audibles (la denominada "vocal behavior") y los no vocales, sino visibles o tangibles (la "non-vocal behavior"), como pueden ser el gesto, la postura, la mirada, la expresión facial, etc.

La "vocal behavior", la actuación sonora o vocal es la que se sirve del medio del habla, cuyos planos y características generales acabo de describir, del "aural medium", como decía Abercrombie. Pero dentro de esta "conducta vocal" se puede aún distinguir entre una "conducta verbal" y una "conducta no verbal" ("verbal behavior"/"non verbal behavior"): la primera es estrictamente lingüística (en ella entran en juego todos los componentes y factores del sistema lingüístico); la segunda incluye procesos lingüísticos y no lingüísticos (por ejemplo, los implícitos en el tono de voz).

Ateniéndonos al "aural medium" y a la "conducta verbal", su riqueza y complejidad saltan a la vista: se trata de un proceso siempre con doble cara, la cara de la forma y la de la materia, la del código ("code") y la del medio ("medium"), la del sistema y la de su realización, necesariamente temporal y, por ende, discontinua, es decir, rítmica, en el sentido más elemental del término.

De las fases de producción del habla anteriormente mencionadas nos interesan aquí especialmente las tres últimas: la organización temporal, la organización prosódica y la organización rítmico-métrica.

naba "marcadores atributivos": indexical features) y lo que LAVER llamó luego "evidential information", transmitida mediante signos del habla que actúan como tales "marcadores".

${ }^{20}$ Características físicas (sexo, edad, salud, etc.), transmitidas por los denominados "marcadores físicos", en las que se incluyen rasgos como la "calidad de voz" ("voice quality"); "marcadores sociales" (status social, ocupación, educación, etc.) e intervienen cosas como el "acento" ("accent") o el tipo de vocabulario; "marcadores psicológicos" (personalidad, situación afectiva, humor), que residen en lo que se suele denominar "tono de la voz" ("tone of voice"). Para todo ello, $c f$. ABERCROMBIE 1967, pp. 7 ss.; LAVER 1994, pp. 13 ss.

${ }^{21} \mathrm{La}$ "regulative information" de LAVER, loc. cit. 


\subsection{La organización temporal del sonus vocis}

En cuanto a la organización temporal, hay que decir ante todo que se produce en términos de duración de los distintos segmentos, de velocidad general del habla y de continuidad de dicha habla.

La duración es el tiempo (normalmente milésimas de segundo) empleado en un suceso de lengua y viene condicionada también por la capacidad perceptiva del oyente, que en condiciones óptimas suele ser muy buena ${ }^{22}$. Los segmentos de la cadena del habla tienen cada uno su duración intrínseca, sus propiedades intrínsecas de duración; pero dicha duración viene además condicionada por una serie muy compleja de factores, como la lengua y el acento del hablante, el "tempo" medio del hablante o su situación paralingüística o como las peculiaridades articulatorias de los segmentos vecinos, la estructura de la sílaba en que figura el segmento, su naturaleza tónica o átona o su posición en la palabra, el número de sílabas de la unidad superior, etc. ${ }^{23}$. Ni qué decir tiene que una cosa es la duración fonética y otra la cantidad fonológica de un segmento o de una sílaba ${ }^{24}$.

El "tempo" es la velocidad al hablar y reside sobre todo en la velocidad de las sílabas. Cada individuo suele tener un "tempo" de habla, variable, por supuesto, según las circunstancias.

Con el "tempo" se halla estrechamente vinculada la "continuidad", es decir, la incidencia de pausas en la corriente del habla, cuántas, cuáles y en qué lugares. Su presencia, tanto si se deben a dudas del hablante como si están hechas a propósito, suele caracterizar el habla de cada individuo. Estas pausas pasan la mayoría desapercibidas para el hablante y para el oyente y, en general, contra lo que, en principio, pudiera parecer, no guardan especial relación con la sintaxis.

"Tempo" y "continuidad" son rasgos extralingüísticos con una función paralingüística en todo caso ${ }^{25}$.

$\overline{22}$ Aunque también se ve afectada por diversos factores, como, por ejemplo, la disminución de la intensidad o el ruido: $C f$. LeHISTE 1970, pp. 9 ss.

${ }^{23}$ Sobre todo esto $c f$. LeHISTE 1970, pp. 9 ss.

${ }^{24} C f$., por ejemplo, Lehiste 1970, pp. 6 ss.; LAVER 1994, pp. 436 ss.

${ }^{25}$ Se distinguen en este sentido el habla continua de la no continua; la fluida, de la interrumpida. Se reconocen "pausas vacías" o silenciosas y "pausas llenas" de material sonoro no lingüístico. 
Pero todo ello se enmarca dentro del proceso cognitivo de planificación y ejecución de las unidades de habla. Dicho proceso es típicamente episódico, lo cual quiere decir que un episodio de habla es cognitivamente planificado como una entidad unitaria y ejecutado y percibido como un acto integrado. A este episodio se lo ha denominado "cláusula fonémica" ("phonemic clause"), que, aunque no siempre, coincide con frecuencia con la cláusula sintáctica.

La cláusula fonémica viene marcada por patrones de tono vocal, ritmo e intensidad. El tono es el más obvio de dichos parámetros $^{26}$. Los patrones tonales de la cláusula fonémica vienen intencionadamente marcados por una palabra, y sólo una, prominente en la percepción, precedida y opcionalmente seguida por otras secuencias de habla menos prominentes. En la estructura de la cláusula fonémica la sílaba acentuada de una palabra importante en cuanto a la información se hace intencionadamente más prominente que las demás sílabas de la cláusula.

\subsection{La organización prosódica del sonus vocis}

En cuanto a la organización prosódica del habla, hay que partir de la idea de que una sílaba resulta más prominente para el que escucha en la medida en que el que habla ha hecho más esfuerzo para articular los segmentos que la constituyen. Y, si todo lo demás es igual, una sílaba es más prominente que otra en la medida en que sus segmentos constituyentes tienen una altura tonal más elevada ("pitch"), una intensidad mayor ("loudness"), una duración más larga ("duration") o un desvío articulatorio mayor a partir de la disposición neutra del tracto vocálico ("articulatory quality").

Los patrones de variación de la prominencia silábica que resultan de la interacción de estos cuatro factores dan a cada lengua una textura característica más allá y por encima del detalle segmental de dicha lengua; textura que resulta del entretejido de tres patrones fundamentales de organización suprasegmental: la organización prosódica, métrica y temporal del material lingüístico.

$\overline{{ }^{26}}$ Sobre la correspondencia de los patrones tonales con la cláusula fonémica, $c f$. LAVER 1994, cap. 15, a propósito de la "intonational phrase". 
Esta organización prosódica opera, pues, fundamentalmente con factores de tono ("pitch") y de intensidad ("loudness") entendidos como rasgos suprasegmentales, distintos, por tanto, de los rasgos de tono, sonoridad o intensidad inherentes a cada segmento y sobreañadidos a ellos ${ }^{27}$. Y afecta esta organización prosódica a unidades suprasegmentales, es decir, a la sílaba y a unidades superiores ${ }^{28}$.

\subsubsection{El tono ("pitch") del sonus vocis}

El tono de la voz pertenece a la dinámica de la voz; es, por tanto, un factor controlable, aprendible y adquirible. Se trata de un concepto perceptivo, cuyo correlato físico es la frecuencia de onda, la frecuencia de vibración de las cuerdas vocales en el momento de la fonación; su correlato acústico es la "frecuencia fundamental", que se mide en hertzios.

La capacidad de percepción del tono en el sistema auditivo humano es muy fina en buenas condiciones.

El "pitch" de la voz fluctúa continuamente mientras habla$\operatorname{mos}^{29}$. Rara vez permanece en una nota mantenida más de una fracción de segundo; la mayoría del tiempo del proceso lo pasa subiendo y bajando. No es una fluctuación al azar, sino que sigue unos patrones melódicos bien definidos (aunque normalmente no reconocidos en general) compartidos por la comunidad y que tienen una considerable importancia lingüística y social.

Que las lenguas e incluso los dialectos no suenan igual en lo que atañe a la fluctuación tonal es algo que todo el mundo sabe; no hace falta un oído especializado para detectar dichas diferencias ${ }^{30}$.

$\overline{{ }^{27} C f}$. Lehiste 1970, pp. 2 ss.

28 Aunque, por supuesto, hay que reconocer interacciones de estos rasgos con los segmentales.

${ }^{29}$ El tono, por supuesto, está realmente presente sólo durante los segmentos sonoros ("voiced"), pero nosotros, sin embargo, escuchamos los patrones melódicos de la fluctuación tonal como continuos; los diminutos espacios que los interrumpen, causados por la presencia recurrente en el habla de segmentos mudos (sin sonido, "voiceless"), pasa desapercibida.

${ }^{30}$ La acusación que con frecuencia hace un grupo a otro de que "cantan en vez de hablar" reconoce simplemente la existencia de patrones melódicos diferentes. Los patrones familiares, de la lengua madre, pasan desapercibidos ("unremarked"): no son oídos en términos de tono musical como tal, sino simplemente como indicaciones inmediatas de significados y actitudes. Los patrones no familiares, en 
En el análisis y descripción fonológicos de los patrones melódicos del habla (algo, por lo demás, común a la melodía del habla -"speech melody"- y a la de la música -"musical melody"-, en cuanto que ambas se basan en patrones de fluctuación melódica) lo importante no es la altura tonal (pitch) absoluta, sino que, al igual que en la música, lo que cuenta es la posición relativa de cada punto respecto a otro dentro del mismo patrón; no su frecuencia en términos de número de vibraciones por segundo. Además, tanto la melodía de la lengua como la de la música pueden ser "transportadas" (cambiadas de tonalidad) sin perder su identidad.

Hay, no obstante, una diferencia fundamental entre ambas melodías: en los patrones de la musical los intervalos entre los puntos son absolutos y constantes; en los de la melodía lingüística son relativos y variables. Así, un patrón en la melodía lingüística puede ser o comprimido o expandido en la dimensión del "pitch" y sigue siendo el mismo patrón, aunque en un caso los intervalos sean más pequeños y en el otro sean más grandes. Esto, en cambio, no puede ocurrir en la melodía musical, pues dicho patrón perdería su entidad tonal, quedaría desafinado ("out of tune"), o incluso sería un patrón diferente.

Y esta misma diferencia entre la música y el habla se puede apreciar en la dimensión temporal o duracional.

La melodía de la voz del hablante en una ocasión concreta no es, como he dicho, un asunto de valores tonales absolutos desarrollados por la voz de sílaba en sílaba. El tono ("pitch") es relativo en dos sentidos: en primer lugar, una sílaba se considera "alta" o "baja" a partir de un juicio perceptivo que hace el oyente en términos de una hipotética ubicación dentro de la gama general en la que se cree que se mueve la voz del hablante ${ }^{31}$. En segundo lugar, el valor tonal de una sílaba dentro de una cadena de habla es valorado relativamente por referencia a las inmediatas.

Así, pues, la melodía de la voz de un hablante en una ocasión concreta es cuestión de una cadena de valores tonales ${ }^{32}$ que el

cambio, en cuanto que no conllevan estas significaciones inmediatas, son escuchados como fluctuación tonal; de ahí lo que se dice de "cantar en vez de hablar".

${ }^{31}$ El más grave tono en la voz de un niño pequeño se puede considerar más alto en términos de frecuencia absoluta que el más alto tono de la voz de un hombre mayor.

${ }^{32}$ Esta definición de "melodía" deja, por ahora, a un lado las cuestiones de ritmo, que también han de ser tenidas en cuenta. 
oyente percibe en la sucesión de las sílabas que va produciendo la unidad de habla, dentro del marco de la gama tonal ("pitchrange") asumida del hablante.

Y dentro de esta "gama tonal" hay que tener en cuenta varios niveles. Uno es la "gama orgánica" del tono del hablante, que es la gama máxima de que es físicamente capaz la voz del hablante, dados los factores biológicamente determinados por la anatomía y fisiología de su faringe. Un segundo tipo de gama tonal es el de la "gama paralingüística" del hablante en el momento: un ajuste dentro de la gama orgánica con propósitos paralingüísticos (sorpresa, angustia, impaciencia, etc. $)^{33}$. El tercer tipo es la "gama lingüística", la gama dentro de la cual varía habitualmente el tono fonológicamente pertinente de la voz del hablante en una conversación no marcada paralingüísticamente y neutra actitudinalmente ${ }^{34}$.

El cuarto tipo de gama tonal, y para nosotros el más importante, es la "extensión tonal" ("pitch-span") fonológica, que es la gama local ("local range") dentro de la cual el hablante organiza los valores relativos de tono con propósitos prosódicos dentro del conjunto o de una parte de una unidad fraseológica particular.

Así, pues, nuestra percepción del valor tonal lingüísticamente relevante de una sílaba dada en una ocasión concreta en boca de un hablante concreto es completamente relativa. El oyente tiene que tener al menos una hipótesis de trabajo (tácita) de la gama orgánica que caracteriza al hablante. Tiene que tener sobreentendida la gama paralingüística en que el hablante se halla. Además debe tener una estimación de la anchura normal de la gama lingüística del hablante y una determinación del valor de la actual amplitud tonal ("pitch-span") del hablante. Una vez que conoce todos estos factores, puede hacer una estimación del valor tonal relativo de cada sílaba.

\footnotetext{
$\overline{33}$ Aquí hay que tener en cuenta también las diferencias entre culturas al respecto.

${ }^{34}$ Las lenguas se diferencian en la ubicación de esta gama lingüística dentro de la gama orgánica: se dice, por ejemplo, que el español se habla, en conjunto, en una gama tonal más baja que el francés. Se diferencian también en la amplitud de la gama lingüística: se dice, por ejemplo, que la gama del mandarín es más amplia que la del francés.
} 
La descripción fonética de los fenómenos tonales se limita convencionalmente a marcar los movimientos tonales relativos dentro de la gama lingüística.

El análisis de la melodía del lenguaje es importante por lo que entraña de soporte de índices afectivos, pero sobre todo por el hecho de que constantemente proporciona patrones de soporte lingüístico que operan simultáneamente con los patrones constituidos a base de rasgos segmentales y con algunos otros rasgos dinámicos.

La fluctuación tonal tiene así una función "indicadora" ("indexical", según Abercrombie) ${ }^{35}$ y una función lingüística; y esta segunda es básica en el sentido de que los signos "indicadores" están sobreimpuestos sobre los patrones de soporte lingüístico.

La fluctuación tonal, en su función lingüística, puede ser denominada "melodía del habla" ("speech melody"); y dicha melodía es parte de la forma de una lengua, exactamente igual que lo son los segmentos.

Las funciones lingüísticas de la melodía son muy variadas, pero fundamentalmente de dos tipos: en un caso los patrones melódicos forman parte de la estructura de la frase ("sentence"); en otro, lo son de la estructura de la palabra ("word"). A lo primero se lo denomina "entonación" (intonation); a lo segundo "tono" (tone $)^{36}$. En cada lengua la función es predominantemente de un tipo o de otro, de modo que las lenguas del mundo se pueden dividir en lenguas de entonación ("intonation languages") y lenguas de tono ("tone languages").

Laver $^{37}$ establecía una distinción entre dos usos fonológicos diferentes del tono, sobre la base del dominio lingüístico en el que los patrones tonales ejercen sus funciones contrastivas. El primero es el empleo del "pitch" en "sistemas tonales" (tone systems"), en los cuales sirve para diferenciar unidades en el nivel de las palabras aisladas o de las sílabas aisladas ${ }^{38}$. El segundo es el uso del "pitch" en "sistemas de entonación", en los cuales sirve para identificar entidades lingüísticas en niveles superiores

\footnotetext{
${ }^{35}$ Cf. supra.

${ }^{36} C f$., por ejemplo, LuQue 2006; 2006b, pp. 13 ss.

37 1994, p. 462 ss.

${ }^{38}$ PIKE 1948.
} 
a la palabra, en el nivel de la frase ("phrase") y de la oración ("sentence").

En la distinción general entre lenguas de tono y lenguas de entonación hay ulteriores diferencias tanto en la forma como en la función de los patrones melódicos ${ }^{39}$. En algunas lenguas de tono, por ejemplo, los patrones pueden servir para distinguir palabras completamente independientes que de otro modo serían iguales. En otras lenguas de tono los patrones pueden tener una función gramatical, marcando la distinción entre tiempos verbales, por ejemplo; sin olvidar, por supuesto, la función culminativa y demarcativa que dicha prominencia tonal ejerce en las palabras identificándolas como tales unidades rítmico-articulatorias. En las lenguas de entonación los patrones melódicos, aparte de su función demarcativa como señaladores de los límites de frase, pueden determinar tipos de oración: declarativa o interrogativa, orden o petición, dependiente o independiente.

Dentro de los sistemas de tono, en los cuales, los patrones tonales contribuyen a la identificación léxica de palabras individuales, se pueden distinguir dos tipos de este tono léxico: uno en que el dominio de la conducta tonal lingüísticamente significativa es la palabra entera; otro, en que el dominio significante es la sílaba ${ }^{40}$.

El tono es usado fonológicamente con una función de entonación cuando los patrones melódicos significativos de movimientos tonales se distribuyen sobre unidades mayores que la palabra. Es lo que ocurre en inglés, lengua que es la que más se ha estudiado en este aspecto ${ }^{41}$.

\subsubsection{La intensidad ("loudness" o "scale") y "sonoridad" del sonus vocis}

La intensidad del medium depende de la fuerza con que el aire es expulsado desde los pulmones mientras vibran las cuerdas vocales. La escala de intensidad de que es capaz la voz humana es muy considerable, pero es un rasgo fácilmente controlable y puede ser automática e inmediatamente controlado por el

\footnotetext{
$\overline{{ }^{39} C}$ f. Abercrombie 1967, p. 108.

${ }^{40}$ LAVER 1994, p. 462.

${ }^{41}$ LAVER 1992, pp. 483 ss.
} 
hablante, acomodándolo a las condiciones en que se encuentre. Los ajustes son muy exactos y el "feed-back" sobre el que se basa este control fino es casi completamente auditivo. El control se hace menos exacto cuando hay interferencias en la escucha ${ }^{42}$.

Cada cual al hablar cubre, en momentos diferentes, una amplia gama de intensidades. Pero individualmente hay muy distintos grados en la intensidad media del habla de cada uno ${ }^{43}$.

La intensidad tiene poca importancia lingüística: esto se ve en el hecho de que un hablante de poca calidad en su intensidad apenas reproduce contrastes de intensidad o casi prescinde de ellos; y esto no importa e incluso puede pasar desapercibido ${ }^{44}$.

Como siempre, hay que distinguir entre medidas físicas y correlatos perceptivos: lo mismo que la altura tonal ("pitch") es el correlato perceptivo de la frecuencia, como medida física, la sonoridad ("loudness") es el rasgo perceptivo relativo al concepto físico de "intensidad".

El oído humano tiene una extraordinaria capacidad sensitiva para la intensidad de los sonidos y puede abarcar y apreciar una gama admirable de intensidades.

Se ha definido la sonoridad de un segmento como su intensidad ("loudness") relativa a la de otros sonidos con la misma duración ("lenght"), "stress" y tono ("pitch"). La "jerarquía de sonoridad" generalmente aceptada, en líneas generales es la siguiente, de mayor a menor:

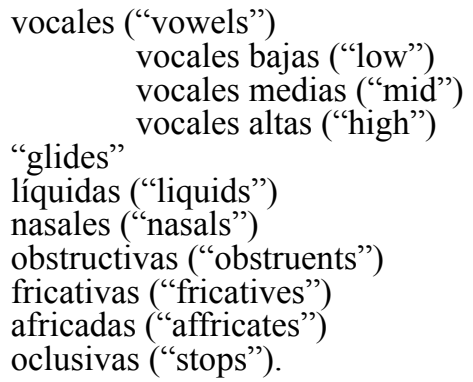

$\overline{{ }^{42}}$ Las mujeres bajo el secador de la peluquería hablan más fuerte que de costumbre o de lo que ellas quisieran hablar en público.

${ }^{43}$ Se ha dicho incluso, aunque esto no está comprobado, que hay diferencias de intensidad media entre lenguas: los egipcios y los árabes parece que hablan con más intensidad que los escoceses.

${ }^{44}$ Sobre todas estas cuestiones sigo a ABERCROMBIE 1967, pp. 95 ss. y a LAVER 1994, pp. 500 ss. 
Asumiendo que se puede establecer un principio de sonoridad relativa para las reglas lingüísticas generales que gobiernan la secuencia segmental dentro de la sílaba, se siguen dos consecuencias: la primera es que cada sílaba estaría internamente caracterizada por un "perfil de sonoridad" a lo largo de sus segmentos constituyentes; la segunda, que todas las sílabas serían susceptibles de ser referidas a sus sílabas vecinas de la unidad de habla en una jerarquía de prominencia silábica relativa ${ }^{45}$.

En general, se puede decir que la intensidad parece explotada en la comunicación lingüística mucho menos que el tono.

Las diferencias de intensidad pueden contribuir a la percepción del "stress" de una sílaba dada en determinadas lenguas.

Más allá de la sílaba el uso lingüístico de la intensidad como rasgo prosódico es comparable en cierto modo al del tono.

\subsection{La organización rítmico-métrica del sonus vocis}

Y pasamos así al último escalón de la producción del lenguaje, el de la organización rítmico-métrica.

Abercrombie $^{46}$ incluía el ritmo entre los rasgos que constituyen la "dinámica de la voz", rasgos todos ellos controlables, aprendibles y, por tanto, adquiribles. Para Laver, la "metrical organization of speech" es el sexto y último elemento de la producción del habla, tras la iniciación, la fonación, la articulación, la organización temporal y la organización prosódica.

El habla depende de la respiración: la corriente de aire no es continua, sino que consiste en una rápida fluctuación que refleja las contracciones y relajaciones de los músculos respiratorios; cada contracción de dichos músculos es lo que los fonetistas denominan "chest-pulse", que coincide con una sílaba ${ }^{47}$; con estos impulsos, reforzándolos, coincide otro tipo de impulso menos frecuente, el denominado "stress-pulse". El ritmo del habla se constituye a base de estos dos tipos de impulsos; es un producto del modo en que se combinan al producir una corriente de aire para hablar. Dicho ritmo está de hecho en la corriente de aire,

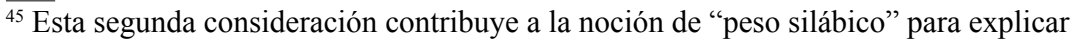
la percepción del ritmo de las unidades fraseológicas.

46 1967, pp. 95 ss.

${ }^{47}$ STETSON 1951.
} 
antes de que en ella tomen cuerpo las vocales y las consonantes de las palabras ${ }^{48}$. En este sentido se puede decir con García Calvo $^{49}$ que el ritmo del lenguaje es "prelingüístico", en cuanto que "común con todo proceso temporal".

El ritmo del habla, como el de otras actividades humanas, surge así de la recurrencia de los movimientos implicados en la producción silábica y en la producción del "stress" ${ }^{50} \mathrm{o}$ de otro tipo de prominencia, como el peso silábico ${ }^{51}$.

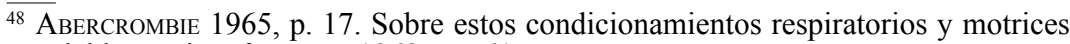
del lenguaje, $c f$. BaLBín 1968, pp. 61 ss.

491979 , p. 251.

${ }^{50}$ Cf. AberCrombie 1967, pp. 96 ss., quien, en consecuencia, reconocía dos tipos de ritmo en el lenguaje: uno determinado por la producción silábica ("syllable-timed"), en el cual la regularidad se halla en la periodicidad de los movimientos de articulación, mientras que los de "stress" son irregulares; otro determinado por el "stress" ("stress-timed"), en el que ocurre al revés.

Siendo las demás cosas iguales, una sílaba es más prominente que otra en la medida en que sus segmentos constituyentes presentan un tono ("pitch") más alto, una intensidad ("loudness") mayor, una duración más larga o un mayor desvío articulatorio del tracto vocálico respecto de la posición neutra.

Semejante caracterización compara tácitamente dos sílabas de igual estructura fonológica. Cuando a igualdad de todo lo demás una sílaba se hace más prominente por exageración de uno de esos cuatro rasgos, se dice que esa sílaba más prominente recibe más acento ("stress").

En esta definición el "acento fonético" ("phonetic stress") es un fenómeno de gradación y la realización fonética de una sílaba se puede decir que muestra un grado mayor o menor de "stress" relativo a la manifestación de alguna otra sílaba. El "stress" se puede así considerar una propiedad fonológica de la sílaba y se pueden establecer inicialmente dos tipos de sílabas, "acentuadas" y "no acentuadas" ("stressed" y "unstressed") usando dos grados de "acento fonológico" ("phonological stress").

La ubicación del acento fonológico en una sílaba concreta de una palabra es una propiedad definidora de dicha palabra; así se habla de "acento de palabra" ("wordstress") o acento léxico ("lexical stress"). Se usa también el término "accent" o "word-accent" para el concepto de "lexical stress", lo cual puede ser útil cuando uno quiere distinguir entre "word-accent" como algo potencial en la ubicación normal del "stress" en una palabra y "stress" como la ubicación de hecho en una ocasión determinada: algo así como distinguir entre "acento" y "refuerzo o énfasis". La manifestación fonética del acento ("stress") varía de una lengua a otra. Para todo ello, $c f$. LAVER 1994, pp. 511 ss.

${ }^{51}$ Un segundo modo por el que las sílabas se pueden diferenciar en prominencia es el "peso silábico" ("syllable weight"), que es en parte un concepto fonológico basado en la constitución segmental de la estructura de las sílabas. Dependiendo de su configuración estructural las sílabas pueden ser consideradas métricamente como "pesadas" ("heavy") y "ligeras" ("light") en prominencia.

Una tercera vía por la que las sílabas pueden alcanzar prominencia, dentro del marco general del peso silábico, es la sonoridad característica de sus segmentos individuales constituyentes. $C f$. LAVER 1994, p. 512 ss. 
La base rítmica del verso y de la prosa es así la misma: ambos no son otra cosa que el resultado de explotar y organizar ciertos aspectos sonoros del habla o, mejor dicho, los movimientos que sustentan dichos fenómenos sonoros. Toda organización rítmica del habla artística, incluso la del más sofisticado de los versos, descansa y se sustenta en los patrones o factores articulatorios y rítmicos intrínsecos al habla normal ${ }^{52}$. El ritmo del habla cotidiana es el fundamento del ritmo del verso en la mayoría de las lenguas ${ }^{53}$.

Por ello los hablantes de una lengua se hayan capacitados para producir y reconocer dichos efectos rítmicos sin necesidad de un estudio especial de prosodia o de métrica; el oyente reconoce el ritmo que emite el hablante en la medida en que, como miembro de la misma comunidad lingüística, mantiene con él lo que Abercrombie denominaba una "empatía fonética"

La cadena hablada se percibe generalmente como pronunciada con un cierto ritmo. La percepción de ese ritmo del habla consiste en el reconocimiento por parte del oyente de una recurrencia cuasi periódica en el tiempo dentro de un tipo dado de unidad del habla. Dicha recurrencia descansa o bien en la mera sucesión discontinua de las unidades de articulación (las sílabas, las palabras o las frases, claramente demarcadas mediante el "stress" u otro tipo de fenómenos como las inflexiones tonales), en cuyo caso nos hallamos más cerca de lo que se suele denominar "ritmo primario", o bien en la aparición más o menos regular (como mínimo, consabida) de unas cimas de prominencia ${ }^{55}$ que marquen unas sílabas frente a otras y den lugar a la alternancia de momentos distintos propia de un "ritmo secundario".

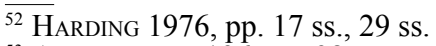

${ }^{53}$ Abercrombie 1967, p. 98.

${ }^{54} 1965$, p. 19.

${ }^{55}$ Prominencia conseguida mediante el acento silábico ("syllable stress") o/y el peso silábico ("syllable weight"). Para una exposición de conjunto de los recientes avances de la fonética en este sentido, véase LAVER 1994, pp. 513 ss, donde se pasa revista a la prominencia conseguida mediante el acento silábico (los mecanismos empleados en su producción, los rasgos acústicos implicados, el "acento de frase", el acento fonológico y sus funciones) o mediante el peso silábico (estructura de la sílaba, tipos según el peso); se estudian luego los diferentes patrones de acento léxico en diversas lenguas (acento fijo/variable, colocación del acento determinada por el peso silábico, acento sintáctico) y, por último, se discute sobre la relación entre la prominencia silábica y el ritmo percibido en las secuencias de habla. 
Por "ritmo primario", o "cardíaco", se entiende la mera secuencia de sucesos o elementos perceptibles, separados entre sí por unos intervalos determinados ${ }^{56}$. En el "ritmo secundario", en cambio, ya no se trata de la simple presencia/ausencia de un fenómeno, sino de una secuencia de, como mínimo, dos fenómenos distintos en alternancia regular o, al menos, consabida ${ }^{57}$. En este ritmo secundario, es decir, en el ritmo propiamente dicho, el proceso supone la sucesión alternativa de sucesos o momentos que se reconocen como diferentes, x y 0 , cuya diferencia es la condición de que uno de ellos, 0 , se reconozca en ese retorno sucesivo como siendo el mismo ${ }^{58}$.

Abercrombie, adoptando las categorías de ritmo lingüístico introducidas por Pike ${ }^{59}$, entendía aún la isocronía como una característica del ritmo lingüístico de todas las lenguas. Dicha isocronía, sin embargo, ha quedado experimentalmente descartada por los estudios fonéticos posteriores, que han optado por una "isocronía subjetiva" en la que todo se reduce a una especie de "tendencia”. Estas teorías orientadas hacia la subjetividad implican

$\overline{{ }^{56} \mathrm{Se}}$ trata, por tanto, de la simple presencia/ausencia de un suceso o estímulo $(\mathrm{x} \quad \mathrm{x} \mathrm{x}$ $\mathrm{x}$...). Es lo que ocurre con el pulso cardíaco o, ya dentro del lenguaje, con la mera sucesión de unidades de producción (sílabas, palabras, frases) en la cadena hablada; dicha cadena, en cuanto que proceso sonoro discontinuo, ya es en sí rítmica en este sentido de ritmo primario.

${ }^{57}$ Se trataría como mínimo de una secuencia $\mathrm{x} \quad 0 \times \mathrm{x} \quad 0 \quad \mathrm{x} \ldots$, o, ya en el lenguaje, por ejemplo, no de una sucesión sílaba-silencio-sílaba-silencio..., sino además de dos tipos distintos de sílabas. Y otro tanto cabría decir en el nivel de las palabras o en el de las frases. $C f$., por ejemplo, Chatmann 1965, p. 22; Allen 1973, pp. 101 ss.

${ }^{58}$ Ahora bien la diferencia entre x y 0 no es simultánea, sino anterior a las nociones lógicas de "identidad" y "diferencia": 0 no retorna porque sea 0 , sino que es 0 porque retorna. Esto además exige que el ritmo se fundamente en una condición lógica, la de que los momentos sean solamente "uno u otro", "o sí o no".

La alternancia rítmica de esos dos momentos x y 0 tiene dos posibilidades y sólo dos: la simple $0 \times 0 \ldots$ o la reduplicativa $0 \times$ × $0 \times$ x $0 \ldots$ No cabe, por ejemplo, una sucesión $0 \times \mathrm{x} \times 0$, pues el $\mathrm{x}$ medial no se identificaría como tal. Tampoco cabe la alternancia $00 \mathrm{xx} 00$, pues en la alternancia reduplicativa $0 \mathrm{xx} 0 \mathrm{xx}$ el elemento $\mathrm{x}$ alterna con 0 en cuanto que reduplicativo (en la alternancia simple $0 \mathrm{x}$ $0 . .$. lo hacía en cuanto que no 0 ) y no cabe, por tanto, otro elemento reduplicado. De estos dos tipos de alternancia rítmica dependen en cierto modo los dos tipos básicos de compases, los binarios y los ternarios: de la alternancia simple o binaria procede el compás o metro ternario, en el que uno de los momentos mide doble que el otro; de la alternancia reduplicada o ternaria procede el compás binario, en el cual valen lo mismo el momento reduplicado (xx) que el no reduplicado (0). $C f$. 591946.

García Calvo 1979, pp. 252 ss. 
que la verdadera isocronía se reduce a un patrón subyacente en la estructura profunda, la regularidad de cuya realización de superficie es perturbada por factores relacionados con la estructura fonética, fonológica y gramatical del habla, a base de unos patrones cuyas complejas reglas están aún por explicar completamente ${ }^{60}$. Aunque, evidentemente, las cosas no son tan simples: las distorsiones rítmicas no parecen venir sólo de esa estructura externa fonológica o gramatical del habla, sino que parecen residir también en la propia naturaleza de la producción del habla; a lo que hay que sumar las variabilidades adicionales impuestas por las diferencias entre hablantes, por el "acento", el estilo, las circunstancias, el humor, etc.

Todo ello hace que el material del habla no sea nunca completamente predecible; el oyente se ve así obligado a recuperar la intención del hablante a partir de la evidencia temporal de la señal lingüística.

Es, pues, fundamental la cuestión de la objetividad o subjetividad del ritmo, la distinción entre "ritmo objetivo" (el constituido por una serie de elementos formales sucesivos) y "ritmo subjetivo" (que reside en unos elementos funcionales que pertenecen a la experiencia subjetiva ${ }^{61}$ ); en otras palabras, determinar si el ritmo se produce (es decir, es cosa del emisor o de la señal en sí) o se percibe (o sea, es algo impuesto por el receptor ${ }^{62}$ ).

La experimentación psicológica y fonética tienen más que comprobada una gran capacidad nuestra para experimentar y percibir el ritmo, capacidad que no se reduce a la simple recepción de los estímulos externos, es decir, a una "percepción analítica",

\footnotetext{
${ }^{60}$ Se trata, pues, de un terreno abierto a nuevas investigaciones y lleno de sugerencias para la fonética y la fonología modernas: $c f$. LAVER 1994, pp. 524 ss. y 533, con indicaciones bibliográficas al respecto.

${ }^{61}$ Las unidades básicas del ritmo son siempre elementos motrices; en la lengua, por ejemplo, las sílabas; en la música, cada uno de las notas o tonos; en la danza, los movimientos del cuerpo. Las diferencias entre las unidades básicas (es decir, entre los tiempos marcados y no marcados de dicho ritmo) pueden establecerse en el ritmo subjetivo sin necesidad de una percepción previa objetiva. Como muy bien dijo De Groot, las diferencias rítmico-funcionales entre las unidades básicas del ritmo objetivo pueden realizarse de cualquier manera imaginable. En cambio, estas diferencias en el ritmo subjetivo son siempre de "Auffälligkeit", es decir, de "capacidad de llamar la atención", de "prominencia".

${ }^{62} C f$., al respecto, por ejemplo De Groot 1932, pp. 177 s. o García Calvo 1975, pp. 18 ss.; LUQUE 1994, pp. 97 ss.
} 
sino que alcanza igualmente a la predicción y expectativa de los estímulos venideros, de forma que fácilmente capta cualquier fallo en la organización de los sucesos rítmicos (la "percepción predictiva") y llega incluso a una "predicción constructiva", producto de nuestra predisposición a imponer patrones rítmicos y estructuras organizativas en aquellas realidades que percibimos (entre ellas, por supuesto, los procesos sonoros o temporales, en general), aun cuando en dichas realidades o secuencias no haya unos estímulos objetivos que induzcan a ello.

La percepción del ritmo es algo inherente en nuestra experiencia de secuencias de sucesos en el dominio temporal: ante todo hay que decir que nuestro sistema auditivo es extremadamente sensible a los fenómenos rítmicos; cualquier oyente capta la regularidad de los golpes rítmicos en la música y percibe perfectamente cualquier desviación de un ritmo establecido; un simple golpe sincopado lo percibimos enseguida claramente como fuera de paso en relación al ritmo de la frase. Es la "percepción analítica".

Y esta capacidad para percibir la desviación rítmica de un único golpe sincopado se asienta en el hecho de que el oyente ha desarrollado una expectación de la ejecución rítmica por referencia a la cual juzga dicha desviación; es la "percepción predictiva".

Pero además la percepción del ritmo, en general, como ya dije, y la del ritmo del habla, en particular, no es sólo analítica y predictiva, sino que puede ser también constructiva; la denominada "percepción constructiva": nuestro sistema cognitivo no se resiste a imponer unos patrones rítmicos en aquello que percibe, aun cuando para ello no exista un estímulo objetivo; es el ejemplo tantas veces aducido de los golpes del péndulo del reloj, objetivamente iguales, sobre los que tendemos a imponer una organización subjetiva y arbitraria, que podemos modificar a voluntad. Y otro tanto puede ocurrir con los pasos al caminar. La lengua ofrece muchos ejemplos de esta tendencia o disposición cognitiva a imponer construcciones rítmicas al material auditivo $^{63}$. Esta formación de hipótesis rítmicas sobre el habla

${ }^{63}$ Experiencias en las que, por ejemplo, se hace que un oyente vaya marcando sobre la mesa los golpes que percibe del habla continua muestran que dicho oyente marca un ritmo más regular que el que conlleva de suyo el material lingüístico. 
se puede decir que forma parte de unas estrategias cognitivas: se trataría en último término de imponer patrones cognitivos sobre el material sensorial con vistas a hacerlo disponible para su procesamiento ulterior.

Pero, dejando a un lado todas estas reservas sobre la variabilidad o la "irregularidad" del ritmo del habla, los fonetistas reconocen hoy como un hecho el que en el ritmo del habla se suman unos fenómenos de prominencia objetiva ${ }^{64}$ con unos procesos de construcción cognitiva. Y entienden que el ritmo percibido es una propiedad del habla que emerge de la coincidencia de sonoridad segmental, peso silábico y "stress" léxico (acento de palabra) en el léxico de una lengua y del empleo pragmático de dicho léxico en las unidades fraseológicas de dicha lengua ${ }^{65}$. A partir de una hipótesis de trabajo como ésta, que concibe el ritmo como una propiedad emergente, se deduce que en una lengua dada, dentro de unidades fraseológicas de "tempo" normal, la percepción del ritmo depende directamente del modo en que es capaz de fluctuar la prominencia de sílabas sucesivas. Y, dado que dicha prominencia relativa se ve como producto de la combinación de la sonoridad segmental con el peso silábico y el "stress" léxico, se intenta explorar en cada caso, en cada lengua, las posibilidades rítmicas que resultan de las permutaciones de dicha combinación ${ }^{66}$.

\section{Las reelaboraciones artísticas del ritmo del habla. Proble- mas de su estudio}

En cualquier hecho de habla van implícitos todos estos factores sonoros: timbres, tonos, intensidades, duraciones, "tempo", unidades de articulación mayores o menores, etc. Todo lo cual se complica si de dicha habla se pretende hacer un uso artístico, si se pretende un habla literaria. Dicha habla artística se sirve, no podía ser de otra forma, de los materiales del habla normal, entre ellos de estos factores o componentes fónicos: "toda obra

\footnotetext{
${ }^{64}$ Que, como ya he dicho, se hace residir en el peso silábico, en la sonoridad de los segmentos de cada sílaba y en el "stress" de dichas sílabas.

${ }^{65}$ Se entiende que algunas de estas unidades fraseológicas (utterances) resultan más regulares rítmicamente que otras dentro de la misma lengua y que pueden además añadir componentes de entonación que afectan a la temporización.

${ }^{66} \mathrm{Cf}$. de nuevo para todo esto, por ejemplo, LAVER 1994, p. 527.
} 
de arte literaria es, antes que nada, un conjunto de sonidos de los cuales emana el significado" "67; hasta en aquéllas en que este medio sonoro queda reducido al mínimo, como puede ser el caso de una novela, el estrato fónico mantiene su importancia decisiva. Imagínese entonces la importancia de este componente sonoro en la expresión literaria antigua, que, incluida la prosaica, iba destinada ante todo y sobre todo a la ejecución oral. En toda obra literaria desempeñan una función de primer rango todos los factores fónicos (las calidades fónicas o fónico-prosódicas de las distintas unidades lingüísticas; la relaciones sonoras entre dichos componentes distribuidos en la cadena hablada, las rimas, las imitaciones sonoras - la denominada "armonía imitativa"-, toda la "orquestación" del habla) y, entre ellos los factores rítmico-métricos, es decir, todo lo referente a la articulación del flujo sonoro del habla ${ }^{68}$.

El lenguaje versificado surge, pues, del habla normal, a base de un proceso de estilización y esterotipación de determinadas formas, algunas de las cuales llegan a fijarse como "formas métricas". Este proceso de estereotipación del habla, a través de esa modalidad de habla que en otra ocasión ${ }^{69}$ he denominado "habla marcada", está en el origen del sistema musical y del sistema versificatorio. Se trata de unas unidades lingüísticas, fraseológicas, que por las razones que sea llamaron especialmente la atención de los hablantes, los cuales en el contexto del rito o del mito las repitieron una y otra vez. A base de ser repetidas e incluso subrayadas con movimientos corporales se va fijando progresivamente su estructura rítmica hasta que queda definida como una auténtica forma métrica, dispuesta ya para ser cumplimentada a base otros materiales lingüísticos. Estas formas métricas o versificatorias, una vez consolidadas constituirán incluso unas unidades autónomas, que no tienen por qué coincidir con las unidades fraseológicas del habla normal ${ }^{70}$. Esto, por supuesto, se da en el verso, la fuerza de cuyo funcionamiento consistirá

${ }^{67}$ WELLEK-WARREN 1953, p. 187.

${ }^{68} C f$. Wellek-Warren 1953, pp. 188 ss.; Herescu 1960, pp. 12 ss., donde se recogen una serie de pasajes que reflejan la especial importancia que los antiguos griegos y latinos concedían a los recursos fónicos en la elaboración artística del lenguaje.

${ }^{69}$ LUQUE 1998; 2002.

${ }^{70}$ Es la independencia que ya les reconocía COHEN 1996. 
precisamente en esa relación dialéctica, esa "violencia organizada", que se establece entre estas unidades rítmico-métricas nuevas, "artificiales" por así decirlo, y las unidades normales del habla (las palabras, las frases, unidades conceptuales y gramaticales, pero también unidades rítmicas naturales de la producción del lenguaje $)^{71}$. En la prosa la situación es distinta: el período en ella es menos autónomo, se halla más sometida a las unidades conceptuales o incluso gramaticales, lo cual no quiere decir que no sea una unidad esencialmente rítmica, antes que unidad conceptual.

En el lenguaje versificado la cadena hablada aparece con una organización especial, basada en la recurrencia de determinados fenómenos (número y/o tipo-largas/breves, tónicas/átonas-de sílabas, distribución de fonemas, morfemas, etc.). Así se caracteriza frente al término opuesto, la denominada "prosa". Pero, como en otras muchas dicotomías lingüísticas, por un lado, el término positivo aparece con frecuencia hipercaracterizado, con marcas distintivas redundantes; por otro, el término negativo (la prosa) puede tener algunas de las características del positivo ${ }^{72}$.

Dichos rasgos y características han de ser, por supuesto, siempre predecibles. Sobre su base se crea en el lenguaje versificado, y mutatis mutandis en la prosa rítmicamente articulada, una trayectoria circular, no lineal, unas unidades que, según he dicho, no tienen por qué coincidir con las oraciones.

El estudio de todo este componente fónico del habla y, en particular, del habla artística, lleva en sí la dificultad de la comunidad de conceptos y, sobre todo, de términos, con la música. Habla y música son dos fenómenos distintos, pero absolutamente paralelos; es más, en último término, son dos desarrollos distintos de una misma célula germinal, la capacidad vocal del hombre y la utilización de dicha capacidad para comunicarse. Si en sí habla y música van esencialmente unidas, lo están también sus respectivos análisis; históricamente así ha sido: la teoría musical se halla en la base del análisis de la articulación sonora del lenguaje que llevan a cabo no sólo la métrica sino también la retórica o la gramática, en sus capítulos de fonética, de ahí que muchos conceptos y términos de aquélla se hayan trasplantado a

\footnotetext{
$\overline{{ }^{71} C} f$. Marouzeau 1949, p. 209.

72 Rodríguez Adrados 1969, p. 640.
} 
los otros ámbitos, dejando abierta una brecha para todo tipo de tergiversaciones y malentendidos: conceptos y términos relativos al tono, a la intensidad, al acento, a los timbres, a las unidades rítmico-métricas, comunes a todos estos ámbitos y, en buena parte, difundidos en todos ellos a partir del campo de la música, requieren siempre una matización para ser entendidos en su justo sentido de acuerdo con el contexto en que se los emplea.

Huelga, por tanto, insistir aquí en los problemas que entraña el concepto y el término "ritmo".

Dos cuestiones, sin embargo, a las que de un modo u otro ya me he referido no pueden ser pasadas por alto en este punto: una es la necesaria pertinencia lingǘstica de los elementos que intervienen en el ritmo artístico del lenguaje ${ }^{73}$; es evidente que en cada lengua para que un elemento pueda ser base de este ritmo o intervenir de en él de algún modo ha de tener carta de naturaleza, es decir, ha ser pertinente en el sistema de dicha lengua.

La segunda cuestión es el carácter convencional de este ritmo artístico. En efecto, en una secuencia rítmica los patrones o intervalos en que se organiza no han de ser necesariamente iguales, ni siquiera regulares; basta con que sean consabidos, convenidos $^{74}$. Esta convencionalidad no afecta sólo al ritmo del lenguaje, cuyo sistema es todo él convencional, sino a cualquier tipo de secuencia rítmica.

\section{El ritmo y el metro}

Pues bien, tras este breve recorrido sobre una serie de perspectivas modernas acerca del ritmo del lenguaje, el natural y el artístico, viene a cuento volver la vista a algunos puntos especialmente relevantes de las antiguas doctrinas al respecto, a la teoría rítmico-métrica que terminó consolidándose en el seno de las antiguas artes musicales, desde donde se difundió al ámbito de la retórica y de la gramática y se perpetuó, en conceptos y términos, hasta nuestros días.

Según una clasificación, al parecer, bastante extendida, dentro de las artes de lo bello, lo que hoy entendemos por "bellas artes", se distinguían dos grupos ${ }^{75}$, un doble trío: de un lado las

$\overline{{ }^{73} C}$., por ejemplo, Mukarovsky 1931; Allen 1973, p. 12.

${ }^{74} \mathrm{Cf}$. MARINER 1971.

${ }^{75} C f$. Westphal 1867 , pp. 4 ss. 
artes "apotelésticas" ( $\tau \varepsilon ́ \chi \nu \alpha \iota ~ \alpha ̉ \pi o \tau \varepsilon \lambda \varepsilon \sigma \tau \imath \kappa \alpha i ́)$, que salen terminadas de mano del artista: la arquitectura, la escultura y la pintura. De otro las artes "prácticas" ( $\pi \rho \alpha \kappa \tau \imath \kappa \alpha i ́)$ o "músicas" ( $\mu$ ov-

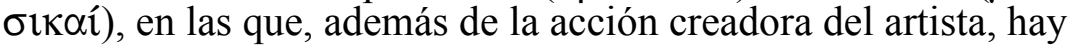
que contar con un acto de ejecución o "performance" (aun cuando, como ocurría sobre todo en etapas más antiguas, el creador -compositor/poeta - y el ejecutante fueran la misma persona): la danza, la música, la poesía. Las tres del primer grupo, además, representaban lo bello estáticamente, en el espacio, mientras que las tres del segundo lo hacían dinámicamente, en movimiento, en su desarrollo temporal.

Todas estas artes, como es lógico, se sustentaban sobre un principio ordenador, que en las estáticas era la figura $(\sigma \chi \eta \mu \alpha)$ u ordenación espacial y en las dinámicas, el ritmo (

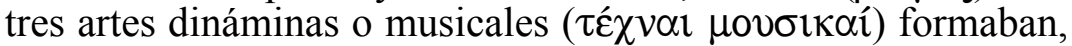
de suyo, un todo unitario, más sólido que el de las espaciales. En ellas, no sólo creador y ejecutante eran, como acabo de decir, la

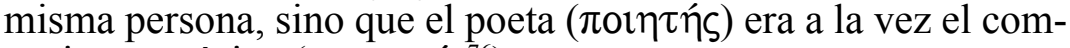
positor o músico $\left(\mu 0 v \sigma 1 \kappa o ́ \varsigma^{76}\right)$.

Pues bien, en el seno de dichas artes musicales, de esta $\mu$ ov-

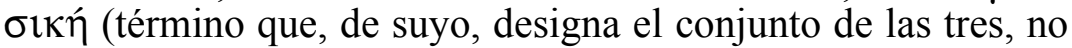
sólo la parte "musical" de dicho conjunto, como ocurre con nuestra "música") se configuró poco a poco un sistema teórico, una

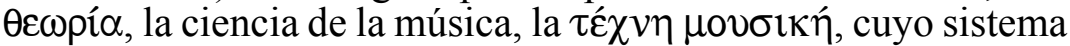

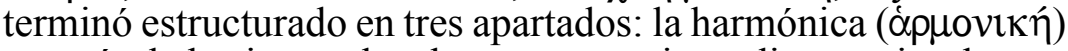
o teoría de los intervalos, las consonancias y disonancias, las escalas y sistemas, etc.; la rítmica ( $\dot{\rho} v \Theta \mu \mathrm{\kappa} \tilde{)})$, o teoría del ritmo y

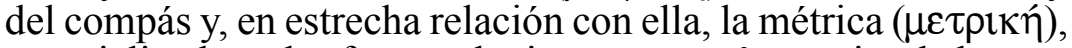
especializada en las formas de ritmo o compás propias de la poesía. Cada una de dichas tres partes tenía, a su vez, una faceta teórica y otra práctica: respectivamente, la "melopea" ( $\mu \varepsilon \lambda$ o $\pi$ otí $\alpha)$,

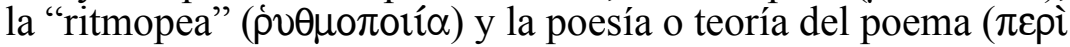

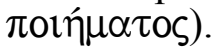

Mas dichas tres disciplinas, que con el tiempo irían cobrando autonomía ${ }^{77}$, no eran en principio más que tres facetas de una

\footnotetext{
$\overline{{ }^{76}}$ Término que, en principio, significa "teórico de la música", antes que "ejecutante" más o menos virtuoso.

${ }^{77} C f$., por ejemplo, LuQue 2001 b.
} 
teoría general que respondía a una realidad unitaria, la de la $\mu$ ovбıк⿰́, en cuyo seno lo que hoy entendemos por música, poesía y danza se hallaban estrechamente vinculadas.

En lo que se refiere a la configuración progresiva de una teoría sobre el ritmo, se entrevé así una primera fase en la que dicho ritmo se concibe ligado a los movimientos corporales de la danza; de ahí términos como "pie" (đoús) o "paso" (ßáoıs) que quedaron luego como designaciones de las unidades básicas de dicho ritmo. Luego, poniendo más los ojos en el componente lingüístico, se pasó a ligar el ritmo al habla, midiéndolo ( $\mu \varepsilon ́ \tau \rho o v)$ a partir del flujo silábico. Hay que esperar a Aristóxeno de Tarento para ver el ritmo entendido como una instancia superior, como algo abstracto u autónomo, por encima de los movimientos de la danza o de las sílabas del lenguaje. Define, en efecto, Aristóxe-

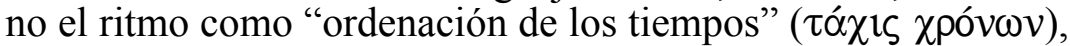
entendiéndolo, de acuerdo con los principios su maestro Aristóteles, como la forma ( $\varepsilon \hat{i} \delta o \zeta)$ que articula la materia (ín $\eta$ ) a

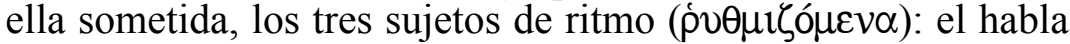
( $\left.\lambda \varepsilon^{\varepsilon} \xi ı\right)$, el componente melódico o tonal ( $\left.\mu \varepsilon^{\prime} \lambda \circ \zeta\right)$ y el movimien-

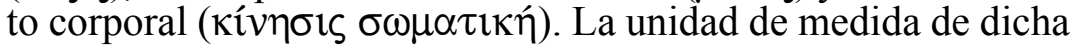
forma rítmica no es, por tanto, el paso, ni tampoco la sílaba,

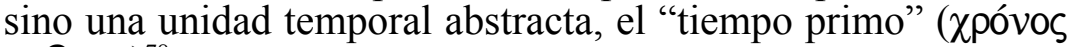
$\pi \rho \hat{\omega} \tau 0 \zeta)^{78}$.

Distinguido, así, el ritmo (jo $\theta \mu \circ \varsigma)$ de su realización

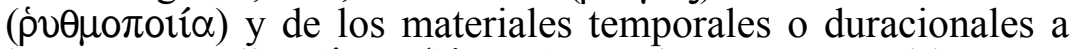
los que se aplica ( $\dot{\rho} \theta \mu 1 \zeta o ́ \mu \varepsilon v \alpha)$, queda en otro sentido estrechamente ligado a otro concepto y término con el que mantiene vínculos estrechos en diversos sentidos, el concepto de "medida" ( $\mu \varepsilon ́ \tau \rho o v)$.

Ritmo y metro $^{79}$ se contraponen como género y especie o como serie infinita y finita, como secuencia indefinida y secuencia delimitada por dicha medida. Se consolida así también

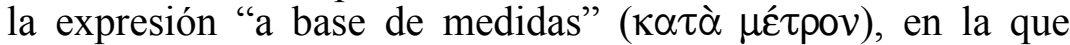
subyace la idea de "metro" como algo más claramente regulado, constituido por unos esquemas fijos, no ya sólo en longitud sino en cuanto a su organización interna; frente a él, en el ritmo no

\footnotetext{
${ }_{78}^{78}$ Sobre todo ello, $c f$. , por ejemplo, LuQue 1987, pp. 23 ss; 1995, pp. 11 ss.

${ }^{79} C f$., por ejemplo, VANDVIK 1937; DREXLER 1941.
} 
habría un retorno regular de elementos establecidos a priori. Se llegará con el tiempo a hablar de versificación "rítmica" o de "ritmos" (rhythmi), distinguiendo la nueva versificación silábica o silábico-acentual frente a la antigua versificación cuantitativa, la "métrica". Ritmo y metro, por otra parte, se contraponen como dos grados distintos de abstracción: la forma rítmica es algo más abstracto y genérico que la forma métrica; el metro es un ritmo secundario lingüísticamente determinado, realizado a base de materiales lingüísticos ${ }^{80}$.

Sobre la base de estas ideas antiguas unos teóricos redujeron luego el concepto de ritmo a los procesos en los que hay una "periodicidad" más o menos regular o, al menos, "consabida" 81 entre el productor y el receptor. Otros, con un criterio más laxo, reconocen como rítmico cualquier proceso temporal o motriz discontinuo ${ }^{82}$. Los primeros casi identifican "ritmo" con "metro" y, en consecuencia, dentro del lenguaje no reconocen más proceso rítmico que el del lenguaje versificado; para ellos hablar de "ritmo de la prosa" sería contradictorio o puramente metafórico ${ }^{83}$. Para los segundos, en cambio, este ritmo de la prosa artística es algo absolutamente normal, como lo es también el ritmo del habla espontánea cotidiana.

En este sentido se orienta una de las tradicionales distinciones que acabamos de ver entre "ritmo" y "metro": frente al metro, el ritmo no consistiría en un retorno regular de elementos establecidos a priori. Sería éste el sentido en que se habla de poemas "de ritmo libre"; poemas que en ese caso poco se diferenciarían de la prosa rítmica ${ }^{84}$.

Por esta vía se puede incluso ampliar y relajar el concepto de ritmo hasta el punto de reconocerlo en cualquier hecho de habla, que conlleva por naturaleza una sucesión de sílabas distinas (tónicas y átonas, largas y breves), de modo que nada fuera propiamente no rítmico, tal como sugería ya Quintiliano:

\footnotetext{
$\overline{{ }^{80} C f}$., por ejemplo, LuQue 1984; 2002

${ }^{81}$ MARINER 1971.

${ }^{82}$ Algo próximo a lo que acabo de decir sobre el "ritmo primario".

${ }^{83}$ Es el caso, por ejemplo, de Wimsatt, que mencionan WelleK-Warren (1953, p. 193, n. 18).

${ }^{84}$ Cf. Primmer 1968 y bibliografía allí citada.
} 
Y, por cierto, en todo el cuerpo y, por así decirlo, en el trecho entero (del habla) se halla inserto el ritmo: pues ni hablar puedo sino a base de sílabas breves y largas, a base de las cuales se hacen los pies. Más, sin embargo, se lo requiere y aparece en las cláusulas ${ }^{85}$.

Pero, si es así, ¿qué distinción establecer entre el habla común y la prosa artística? Viene entonces aquí otro tipo de concepción del ritmo no ya a base de unos patrones más o menos regulares, surgidos de la alternancia de dos tipos de sílabas, sino desde la óptica de la membración, de la responsión, de la estructura armoniosa. Así enfocado, el ritmo se desliga de sus lazos con las sílabas y sus posibilidades de prominencia en virtud de las modulaciones prosódicas (el tono, la intensidad, la duración) y se le abre la puerta al ámbito de las otras unidades de producción (unidades rítmicas primarias) del habla, las palabras y las frases. También estas unidades mayores pueden establecer patrones de retorno más o menos regular, como lo hacen las sílabas, pero, sobre todo, dan pie y constituyen el sustento de una articulación armónica del habla donde tengan cabida todo tipo de responsiones o correspondencias.

Se da por esta puerta entrada en la producción del ritmo a una gama infinita de factores lingüísticos: todo tipo de elementos del lenguaje, formales y/o de contenido, pueden intervenir en esta articulación del habla a base miembros que se corresponden e interrelacionan armónicamente, rítmicamente, de muchas maneras posibles. Cualquier elemento formal o de contenido que se puede repetir u organizar en disposición de correspondencia con otros puede ser susceptible de formar parte de la organización rítmica del habla.

Es éste, como veremos, el sentido en que se orienta la articulación rítmica de la prosa artística promovida por los rétores antiguos, a base de dejar en ella bien establecidas unas unidades de articulación periódica, con unos límites bien marcados y con una estructura interna armónica ${ }^{86}$.

En este sentido irá en buena parte la distinción antigua entre la organización rítmica del lenguaje versificado (secuencia de

$\overline{{ }^{85}}$ Et in omni quidem corpore totoque, ut ita dixerim, tractu numerus insertus est: neque enim loqui possum, nisi e syllabis brevibus ac longis, ex quibus pedes fiunt. Magis tamen et desideratur in clausulis et apparet...: IX 4,61.

${ }^{86} C f$., por ejemplo, LuQue 2001. 
medidas de base cuantitativa, silábica o silábico-cuantitativa) y la organización rítmica de la prosa (articulación rítmica a base de unas unidades fraseológicas bien marcadas ${ }^{87}$ mediante diversos elementos formales y de contenido de la propia dicción; elementos entre los que se incluyen ciertos patrones rítmicos del tipo de los que caracterizan en su totalidad al lenguaje versificado).

Pero todas estas nociones no se han delimitado ni se delimitan siempre con la suficiente claridad y entre los términos que las designan las interferencias son frecuentes. Sin ir más lejos, en la pareja básica ritmo/metro es lógico que esto ocurra, cuando hasta los propios conceptos se imbrican mutuamente; todo metro es rítmico y todo ritmo conlleva un cierto tipo de medida. Todo ello hace que los problemas terminológicos no sean infrecuentes en estos terrenos, y aún más cuando se trata de textos como los ciceronianos que no persiguen una exposición estrictamente técnica.

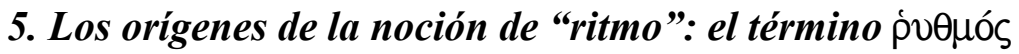

Y, por fin, cerremos estas reflexiones con una breve consi-

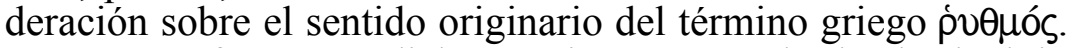
Parece, en efecto, que dicho término no tuvo desde el principio una relación clara y exclusiva con los procesos motrices o temporales, sino que se presenta, en general, con un doble sentido: por un lado, simplemente el sentido de regularidad, forma, ley; por otro el de flujo regular, repetición regular. Así se puede ver en Aristides Quintiliano, quien, aun manteniéndose en la línea de Aristóxeno, dejaba constancia expresa de esta multiplicidad

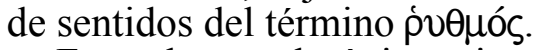

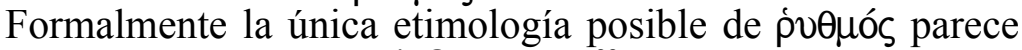
ser la que lo relaciona con $\rho \varepsilon \hat{\imath} v$, "fluir" semántica entre "ritmo" y "fluir" no parece tan clara; es más, resulta difícil. La filología moderna no se ha mostrado unánime al respecto, ni, en consecuencia, tampoco en la determinación del

\footnotetext{
${ }^{87}$ De manera especial en sus comienzos y en sus finales: sententiae verbis finiantur eorumque verborum numero nascatur ab proceris numeris ac liberis ... Et, si primi et postremi [illi] pedes sunt hac ratione servati, medii possunt latere (Cic. De or. III 49, 191); nam ut initia clausulaeque plurimum momenti habent, quotiens incipit sensus aut desinit, sic in mediis quoque ... (Quint. IX 4,67).

${ }^{88} C f$. FRISK 1960, s.v.
} 


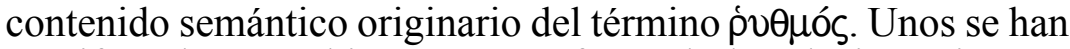
manifestado más abiertamente a favor de la relación "ritmo""fluir"; es el caso de Schröder ${ }^{89}$, de Fritz ${ }^{90}$, de Waltz" ${ }^{91}$, más recientementem de Wolf ${ }^{92}$. Otros, como Jaeger ${ }^{93}$, Leemans ${ }^{94}$, Benveniste $^{95}$ o Primmer ${ }^{96}$ han mostrado reparos más o menos fuertes a esta relación.

Waltz, por ejemplo, insistía en que la noción originaria de

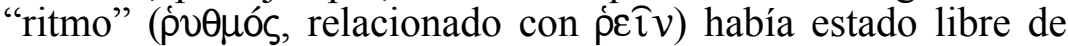
otras, como "medida" o "simetría", que se le habrían ido asociando luego arbitrariamente con el uso: la idea originaria habría

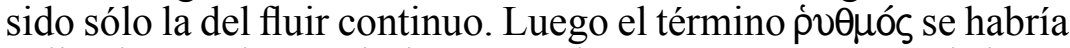
aplicado a todo movimiento continuo y suave, como el de un arroyo que fluye, y que produce sobre nosotros una impresión agradable $^{97}$. De ahí habría pasado a designar los movimientos sonoros del canto, de la música, de la poesía, a la prosa retórica, indicando "la fluidité du mouvement continu, interrompu, ...que constitue la sucession des sons instrumentaux ou vocaux". En Grecia este término no se habría visto mezclado en un principio

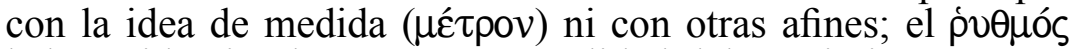
habría sido simplemente "una cualidad del movimiento". Pero luego, incluso ya entre los griegos, a esta noción de "ritmo" se le habrían ido agregando otras, ajenas a su etimología, como las ideas de "regla", "medida" u "ordenación simétrica", en lo cual es posible reconocer la influencia de Pitágoras con su culto por el número. Así se modifica la noción primitiva de "ritmo" tanto en los filósofos como en el habla de la calle. De este modo, en

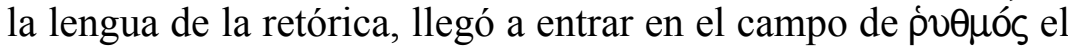
término ảpt $\theta \mu$ ó $/$ numerus $^{98}$, que no es un verdadero equivalente

$\overline{89} 1918$.

${ }^{90} 1938$.

${ }^{91} 1948$.

921955.

931933 .

941948.

${ }^{95} 1951$.

96 1968, pp. 19 ss.

${ }^{97}$ WALTZ 1948, p. 112.

${ }^{98}$ Curiosamente WALTZ consideraba a los romanos como los verdaderos responsables de esto. Por obra de CíERón [sic] se habría consagrado con este sentido el término numerus. 


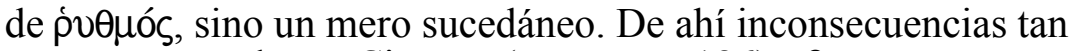
graves como el que Cicerón (De or. III 186) afirmara que $n u$ merus in continuatione nullus est, lo cual contraviene la idea de "movimiento o flujo continuo" que Waltz pretendía reconocer en

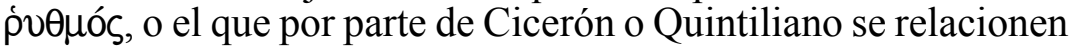
estrechamente numerus y modus, rhythmus y metrum $^{99}$.

Jaeger ${ }^{100}$, por ejemplo, a propósito del fragmento $67 \mathrm{de} \mathrm{Ar}-$ quíloco ${ }^{101}$, escribía:

La concepción de donde brota este ethos soberano se eleva por encima del consejo puramente práctico de mantener la moderación en la vida cotidiana, hasta la intuición de un 'ritmo' en la totalidad de la existencia humana. En ella funda Arquíloco su exhortación al propio control y la advertencia ante todo desbordamiento sentimental, en la alegría y en la pena, es decir, ante toda la constricción exterior (...). En este 'ritmo' es acaso posible percibir ya algo del espíritu de la filosofía natural y del pensamiento histórico que, por primera vez, avanza hacia la intuición objetiva de una legalidad en el curso natural de la existencia. Heródoto [I 207] habla derechamente de los 'ciclos de las cosas humanas' y por ello entiende, ante todo, los altos y los bajos de la fortuna.

Ello no debe conducirnos, sin embargo, a pensar el ritmo de Arquíloco como algo fluyente, que es la consecuencia natural de lo rítmico para el sentimiento moderno, que suele apoyarse en una derivación etimológica de la palabra, de ṕć , 'fluir'. La historia real de la palabra se opone claramente a esta interpretación. La aplicación de la palabra al movimiento de la danza y la música, de la cual deriva nuestra palabra, es secundaria y oculta la significación fundamental. Debemos ante todo preguntarnos cómo entendieron los griegos la esencia de la danza y de la música. Y esto se halla brillantemente ilustrado por la significación fundamental tal como se muestra ya en el verso de Arquíloco. El hecho de que el ritmo 'mantenga' al hombre -he traducido antes los 'mantiene en sus límites'- excluye ya toda idea de un flujo de las cosas. Pensemos en el Prometeo de Esquilo, que se halla sujeto, inmóvil en su roca, con grillos de hierro y dice: me hallo encadenado aquí en este 'ritmo'102; o en el Jerjes, del cual dice Esquilo que ha encadenado el flujo del Helesponto y ha 'dado otra forma (ritmo) al

\footnotetext{
99 Ignorando a ARISTÓTELES, por ejemplo, Rhet. III 9,3.

100 1933, pp. 126 ss.

101 "Ni debes pavonearte ante el mundo como vencedor ni hundirte y lamentarte como vencido; alégrate con lo que es digno de alegría, no te rindas con exceso ante la

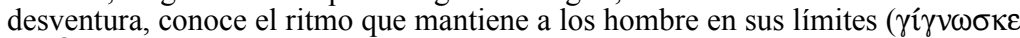

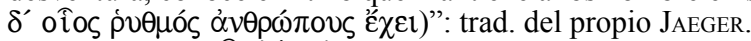

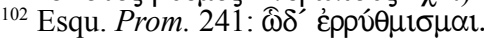


curso del agua' ${ }^{103}$, es decir, lo ha transformado en un puente y lo ha sujetado con firmes ataduras. Ritmo es aquí lo que impone firmeza y límites al movimiento y al flujo. Y esto es únicamente lo que significa para Arquíloco. También Demócrito habla de ritmo del átomo en el antiguo y auténtico sentido y entiende por ello no su movimiento, sino, como ya Aristóteles certeramente lo interpretó, su 'esquema' 104 . Y así entendieron también los intérpretes antiguos las palabras de Esquilo. Evidentemente, cuando los griegos hablan del ritmo de un edificio o de una estatua no se trata de una transposición metafórica del lenguaje musical. Y la intuición originaria que se halla en el fondo del descubrimiento griego del ritmo, en la danza y en la música, no se refiere a su fluencia, sino, por el contrario, a sus pausas y a la constante limitación del movimiento.

Más adelante ${ }^{105}$ pondera Jaeger la enorme importancia del número (ảpi $\theta \mu$ ós) y de la aritmética, puestos en íntima relación con la música dentro de la tradición pitagórico-platónica; relación de donde procede la consideración de las leyes numéricas del mundo sonoro, base de la teoría filosófica sobre la acción educadora de la música. Esta unión entre aritmética y música dio lugar a las más fecundas ideas pedagógicas de los griegos: "sólo el conocimiento de la esencia de la armonía y del ritmo que surge de ella sería bastante para asegurar a los griegos la inmortalidad en la historia de la educación humana". Es un conocimiento aplicable a todas las esferas de la experiencia humana, incluida la organización del cosmos. La armonía expresa la relación de las partes con el todo. En ella se halla implícito el concepto matemático de proporción. "Sólo si alcanzamos a comprender el dominio ilimitado de este concepto en todos los aspectos del pensamiento griego de los clásicos y de los tiempos posteriores, llegaremos a una representación adecuada de la fuerza normativa del descubrimiento de la armonía".

Concepto de armonía, que se expresa en griego con un término cuya raíz (*ar-), en sus diversas posibilidades y grados de realización silábica, se comprueba como altamente productiva en el ámbito de las lenguas indoeuropeas ${ }^{106}$, en las cuales ha dado lugar a una serie de palabras que, como sugería García

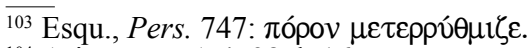

${ }^{104}$ Arist., Met. A 4, 985 b 16.

105 1933, pp. 162 ss.

${ }^{106} C f$., por ejemplo, POKORNY 1969, pp. 55-63. 
$\mathrm{Calvo}^{107}$, hacen de esta raíz el semantema técnico por excelencia; palabras que apuntan siempre a las nociones de "discontinuidad", de "ensamblamiento" en su doble faceta de análisis y de síntesis (desmembración o división en piezas y combinación de dichas piezas en un conjunto).

Con este concepto de armonía aparece, como hemos visto, íntimamente relacionado el de ritmo ( $\dot{\rho} v \theta \mu o ́ s)$, al igual que el de

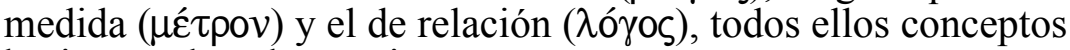
básicos en la cultura griega:

Los conceptos de ritmo, medida y relación se hallan en íntima conexión con él o reciben de él su contenido más preciso. Lo mismo para el concepto de cosmos que para el de la armonía y el ritmo, el descubrimiento de la 'naturaleza del ser' es el estadio previo para llegar a su trasposición al mundo interior del hombre y al problema de la estructuración de la vida.

Volverá Jaeger sobre la misma idea a propósito de la Repúbli$c a$ de Platón, donde sí aparece ya ṕ $\theta \mu$ ós con su nuevo sentido de "ordenación del movimiento":

Inseparable de la armonía es el ritmo, o sea el orden en el movimiento $^{108}$. Ya dijimos más arriba que la palabra griega por su origen, no entraña la acepción de movimiento, pero expresa en numerosos pasajes el 'momento' de una posición u ordenación fija de objetos. La mirada del griego la reconoce tanto en estado de quietud como en estado de movimiento, en el compás de la danza, del canto o del discurso, sobre todo si es en verso (...) la teoría del ethos en la armonía y el ritmo. De esta teoría se deriva lo que Platón enseña acerca de la selección de las armonías que expresan el ethos del hombre valiente o del hombre sereno. Y de entre la riqueza de las clases de ritmos no selecciona tampoco más que aquellas que imitan la esencia de estas dos actitudes morales de la voluntad. Por donde la teoría del ethos se erige en el principio común tanto de la paideia musical como de la paideia rítmica. Pero ya el mero hecho de que tome esta teoría de Damón, el mayor teórico musical de la época socrática, demuestra que no estamos ante algo específicamente platónico, sino ante una

$\overline{107} 1975$, pp. 14 ss. Previamente presenta una rica enumeración de palabras relacionadas con esta raíz organizada en cinco apartados correspondientes a las nociones de "ajustar, justo, preciso", "juntura, miembros, articulación”, "ensamblar, conjunto, estructura", "correspondencia, harmonía, agrado, arte, manera" y "orden, cuenta, número, razonar, hablar, discutir".

${ }^{108}$ Rep. 399 E. 
concepción de la música peculiar de los griegos, que de un modo consciente o inconsciente fue decisiva desde el primer momento con respecto a la posición dominante que la armonía y el ritmo desempeñan en la cultura griega ${ }^{109}$.

He considerado oportuno transcribir estas largas citas de Jaeger porque en sus palabras queda más que patente no sólo el

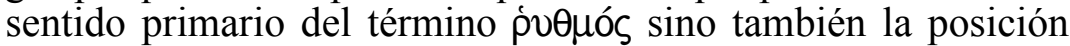
cardinal del concepto de "ritmo" en el pensamiento y en la cultura griega.

Desde esa idea partirá Benveniste, en su decisivo trabajo sobre la noción de "ritmo" y su expresión lingüística, cuyas líneas generales no se apartan de las que acabamos de ver en Jaeger:

La notion du 'rythme' est de celles qui intéressent une large portion des activités humaines. Peut-être même servirait-elle à caractériser distinctivement les comportements humains, individuels et collectifs, dans la mesure où nous prenons conscience des durées et des succesions qui les réglent, et aussi quand, par-delà l'ordre humain, nous rejetons un rythme dans les choses et dans les évènements.

Así inicia su estudio ${ }^{110}$ de nuestro término, generalizado luego desde Grecia y Roma a todo el pensamiento occidental. E inmediatamente pasa a reconocer que, a pesar de que morfológicamente no hay dificultad para relacionar $\rho v \theta \mu o ́ s$ con $\rho \varepsilon \imath \hat{\imath} v$, "fluir", los lazos semánticos resultan, sin embargo, imposibles en cuanto se examinan las fuentes más antiguas. Los textos de Demócrito, los de Heródoto, los de los líricos, los de la tragedia, los de la prosa ática del siglo v (Jenofonte o Platón), los de Aris-

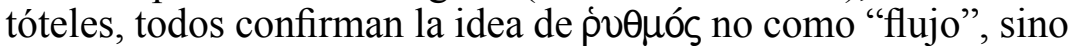
como $\sigma \chi \bar{\eta} \mu \alpha$, es decir, "estructura", "figura", "forma".

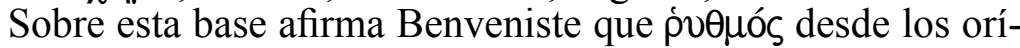
genes al período ático no significó nunca "ritmo" en nuestro sentido moderno; que nunca se aplica al movimiento regular, por ejemplo, de las olas; que su sentido constante a través de todas las variadas condiciones de su empleo es el de "forma distintiva", "figura proporcionada", "disposición"111.

$\overline{109} 1933$, pp. $620 \mathrm{~s}$.

110 1951, p. 327.

${ }^{111} \mathrm{Y}$ otro tanto ocurre con sus derivados o compuestos, nominales o verbales. 
Ello no conduce a Benveniste tanto a discutir la relación de

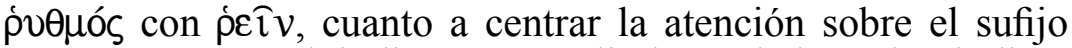
- $\mu$ o , que, según él, indica no cumplimiento de la acción indicada por la raíz, sino modalidad particular de dicho cumplimiento, tal como se presenta a los ojos. Así, por ejemplo, frente a $\chi p \bar{\gamma} \sigma ı$,

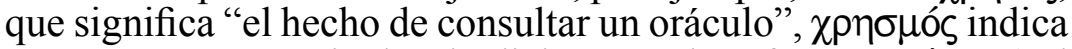
"una respuesta particular de dicho oráculo"; frente a Aćбıs ("el hecho de colocar"), $\theta \varepsilon \sigma \mu$ ós ("una disposición particular"); frente a $\sigma \tau \alpha ́ \sigma ı \varsigma$ ("el hecho de estar en pie"), $\sigma \tau \alpha \sigma \mu o ́ \varsigma$ ("la manera de estar").

En lo que a radicales se refiere, la diferencia entre $\sigma \chi \widehat{\eta} \mu \alpha$ y

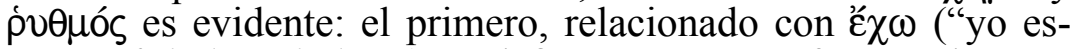
toy"; cf. habeo, habitus) se define como una "forma" de estar fija, realizada o puesta de algún modo como un objeto; ṕ⿴囗十ós, en cambio, según los contextos, designa la forma en el instante en que es asumida por lo que se mueve, por lo que es móvil, fluido y no tiene consistencia orgánica; es una "forma", por así decirlo, provisional, momentánea, modificable.

Si tenemos en cuenta que $\varepsilon^{\varepsilon} \hat{\imath} v$ constituye en la filosofía jonia, en Heráclito, Demócrito, el predicado esencial de la naturaleza y de las cosas, se comprenderá entonces fácilmente que

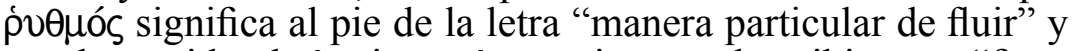
que haya sido el término más propio para describir unas "figuras", "configuraciones" o "disposiciones" que no tienen fijeza ni necesidad natural, sino que son resultantes de una disposición siempre en trance de cambiar. La elección de un derivado de

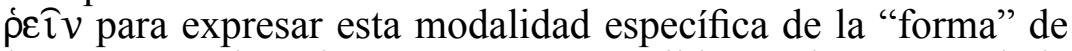
las cosas es algo plenamente comprensible en el contexto de la filosofía que la inspira.

En todo ello estaban ya implícitas las condiciones para que

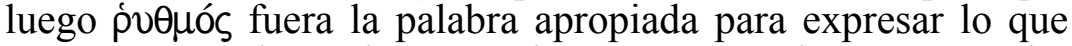
nosotros entendemos hoy por "ritmo". Y es precisamente en Platón donde se detecta el paso desde la antigua noción de "ritmo" a

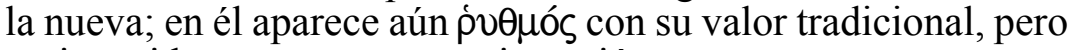
enriquecido con una nueva orientación:

Mas, querido, cuando captes todos los intervalos ( $\delta 1 \alpha \sigma \tau \eta \mu \alpha \tau \alpha)$

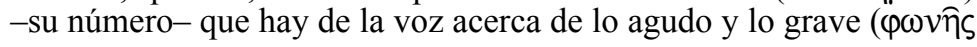




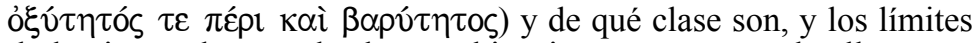
de los intervalos y todas las combinaciones que nacen de ellos -que los antepasados reconocieron y nos transmitieron a sus sucesores con el nombre de armonías (ápuovías), y, por otra parte, que se dan otros accidentes semejantes que residen en los movimientos del cuerpo, los cuales $<$ medidos mediante números $\left(\delta \imath^{\prime} \dot{\alpha} \rho \imath \theta \mu \widehat{\omega} \nu \mu \varepsilon \tau \rho \eta \theta \varepsilon ́ v \tau \alpha\right)>$ dicen que deben ser llamados ritmos y metros ( a la vez hay que considerar que así hay que atender a toda unidad y

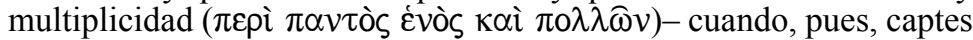
eso de este modo, entonces habrás llegado a ser sabio ${ }^{112}$.

Heráclito (...) Dice, en efecto, que lo uno 'siendo discordante en sí concuerda consigo mismo', 'como la armonía del arco y de la lira'. Mas es un gran absurdo decir que la armonía (ópuovíav) es discordante o que resulta de lo que todavía es discordante. Pero, quizás, lo que quería decir era que resulta de lo que anteriormente ha sido dis-

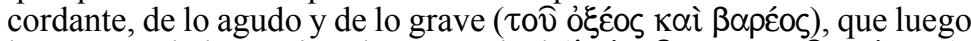

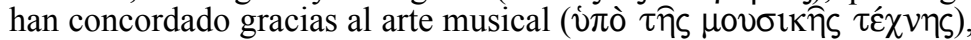
puesto que, naturalmente, no podría haber armonía de lo agudo y de lo grave cuando todavía son discordantes. La armonía, ciertamente, es una consonancia, y la consonancia es un acuerdo ( $\dot{\eta}$ yàp ópuovía

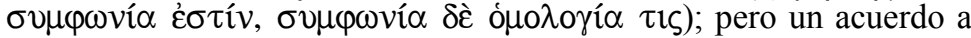
partir de cosas discordantes es imposible que exista mientras sean discordantes y, a su vez, lo que es discordante y no concuerda es imposible que armonice. Justamente como resulta también el ritmo de lo rá-

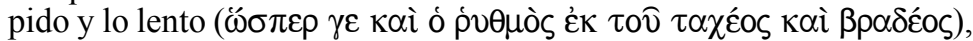
de cosas que en un principio han sido discordantes y después han concordado. Y el acuerdo en todos estos elementos lo pone aquí la música (...) Y la música es, a su vez, un conocimiento de las operaciones amo-

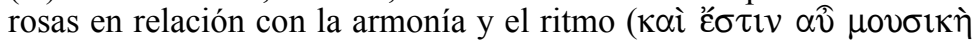

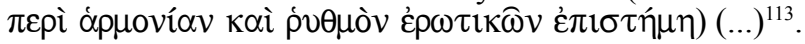

Este orden en el movimiento ha recibido precisamente el nombre

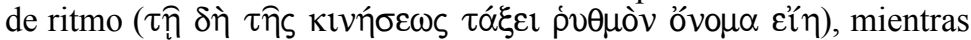
que al orden de la voz ( $\tau \hat{\eta} \varsigma \varphi \omega v \hat{\eta} \varsigma$ ), donde lo agudo y lo grave se

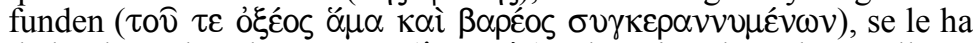
dado el nombre de armonía ( $\alpha$ p $\mu$ ovía) y la unión de ambos se llama arte coral $(\chi 0 \rho \varepsilon i ́ \alpha)^{114}$.

${ }_{112}$ Phil. 17 c-e; trad. Ma A. Durán, Madrid, 1992.

${ }_{113}$ Symp. 187 b-c, trad. M. Martínez Hernández, Madrid, 1993.

${ }^{114}$ Leg. 665 a. Prácticamente de la misma época que estos textos platónicos es el pasaje de citado por CASTILlo (1968, p. 287), en el que se asocia ya la idea de ritmo a la organización de la prosa artística: "Porque hay algunos prosistas que ... prefirieron escribir discursos que no se refieren a vuestros contratos, sino que se dirigen a todos los griegos, que atañen a la ciudad y a todo el público que asiste a una fiesta solemne. Estas obras, según todos dicen, se acomodan más a las composiciones 
Nótese en estos pasajes la expresa relación del ritmo con la armonía, ambos dentro de la música como "formas" proporcionadas, concordantes. La definición de "ritmo" que se da en el tercero de ellos (Las leyes) no se aparta del sentido tradicional del

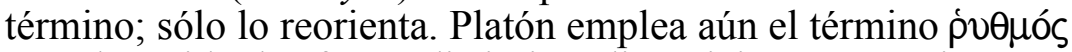
con el sentido de "forma distintiva, disposición, proporción"; su innovación consiste en aplicar este sentido a la forma del movimiento del cuerpo humano, a la danza, y a la disposición de las figuras que surgen en este movimiento. Lo decisivo aquí, como se ve por el pasaje del Filebo, está en la noción de un ṕ日uòv

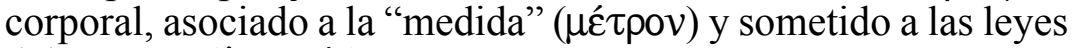

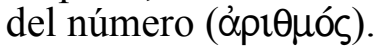

Detrás de todo esto reconocía Benveniste un largo proceso de reflexión sobre la naturaleza de las cosas. A nosotros, en cambio, después de tantos siglos, la noción de ritmo nos resulta algo natural, necesariamente inherente a las formas articuladas del movimiento; y esto hasta tal punto que nos resulta difícil creer que no fue así desde el principio, que fue preciso el esfuerzo de muchos pensadores para llegar a definir y a tomar conciencia de dicha noción ${ }^{115}$.

No nos debe pasar tampoco desapercibida la relación que en el Filebo se establece expresamente entre ritmo ( $\dot{v} \theta \mu$ uós) y número (ảpl $\theta \mu o ́ \varsigma)$. Dicha relación aparece igualmente explícita en otros textos antiguos. Tal es el caso de la Retórica de Aristóteles:

Lo primero, en efecto, no resulta convincente (porque da la impresión de artificioso) y al mismo tiempo distrae, pues hace que $<\mathrm{el}$ oyente $>$ esté sólo pendiente de cuándo volverá otra vez la cadencia. Ocurre, pues, como con los niños, que a la pregunta de los heraldos ‘a quién escoge el liberto por patrón?' se adelantan a responder '¡A Cleón!' En cambio, lo que no tiene ritmo resulta ilimitado ( $\tau$ ò $\delta \grave{~}$

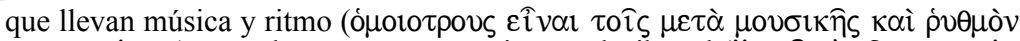

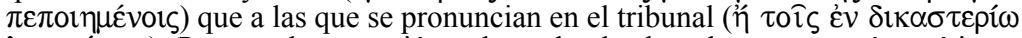
$\lambda \varepsilon \gamma o \mu \varepsilon ́ v o r \varsigma)$. Pues en la expresión aclaran los hechos de manera más poética y adornada e intentan utilizar los pensamientos más dignos y nuevos y además organizan todo el discurso con otros brillantes y útiles procedimientos. Al oírlos, todos

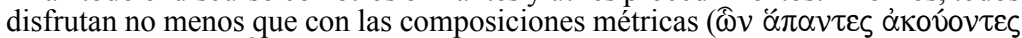

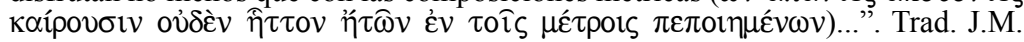
Guzmán, Madrid, 1979.

${ }^{115}$ BENVENISTE 1951, p. 335. 


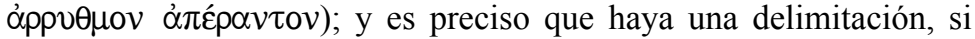
bien no en virtud del metro ( $\mu \grave{\eta} \mu \varepsilon ́ \tau \rho \omega)$, pues lo indeterminado no es

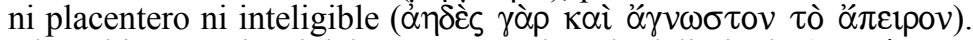
Ahora bien, en virtud del número queda todo delimitado ( $\pi \varepsilon \rho \alpha i ́ v \varepsilon \tau \alpha$ r

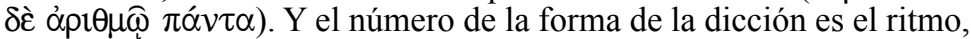

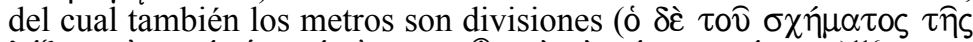

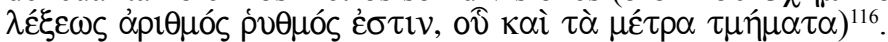

Y un poco más adelante (1409b 5) volverá a afirmar la presencia del "número" en la dicción organizada rítmicamente a base de períodos:

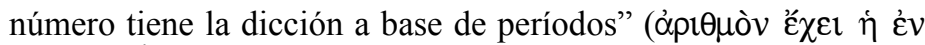
$\left.\pi \varepsilon p 1 o ́ \delta o เ \varsigma \lambda \varepsilon_{\varepsilon}^{\prime} \xi \varsigma\right)$.

En Isócrates se lee igualmente:

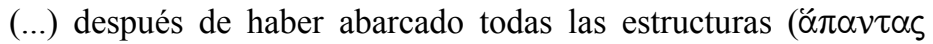

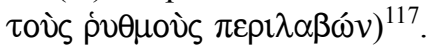

Dentro de este mismo ámbito de la retórica veremos más adelante a Dionisio de Halicarnaso utilizar el término ópı $\theta \mu o ́ s$ para referirse al ritmo de la prosa ${ }^{118}$.

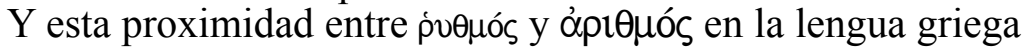
pudo contribuir a que el latín recogiera el significado de ambos términos con uno solo, numerus ${ }^{119}$ :

Numerus vocatur qui Graece po $\theta \mu$ ós dicitur ${ }^{120}$.

La equivalencia o proximidad entre los dos conceptos y términos no ha parecido siempre fácil a los estudiosos. Ya hemos

$\overline{{ }^{116} \text { Rhet. III 8, 1408b } 22 .}$

${ }^{117}$ Busiris 16,1 s.

${ }^{118}$ Dem. 54, 1119,1.

${ }^{119} C f$. Castillo 1968, p. 288, en donde se encontrará también lo fundamental sobre

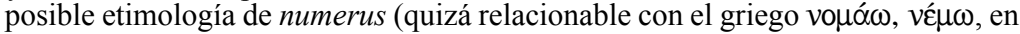
donde se halla implícita la idea de "distribución") y sus significados principales en los primeros empleos documentados en latín: nociones de cantidad, de número, clase, categoría o importancia. Implicando la idea de "ritmo" aparecería por primera vez quizá en el epitafio de Plauto que recoge Aulo Gelio (I 24) y luego en Lucrecio (II 629 ss.; 635 s.; IV 768 ss.; V 1401 s.), en Catulo $(50,5)$ y en la Rhet. ad Her. IV 44,12.

${ }^{120}$ Cic., Or. 67. Cf. al respecto Cocchia 1919. 
visto al respecto las afirmaciones de Waltz; afirmaciones, por cierto, no bien fundadas, como ya dije, ni bien documentadas. Ya antes habían mostrado sus escrúpulos al respecto Christ y Graf $^{121}$. Para el primero ${ }^{122}$, por ejemplo, una vez entendido el ritmo en palabras de Aristóxeno como "ordenación de tiempos"

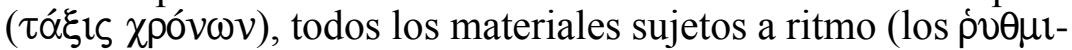

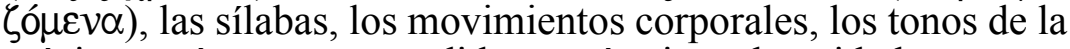
música, tenían que ser medidos en términos de unidades tempo-

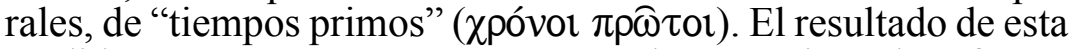
medida se expresaría en números. De ahí que Aristóteles afirma-

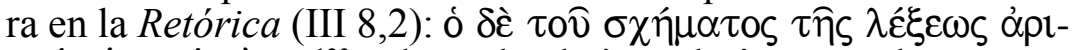

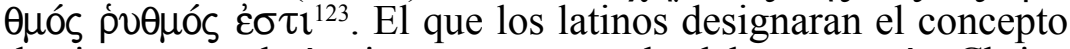
de ritmo con el término numerus pudo deberse, según Christ, a consideraciones como las que acababa de exponer o bien al

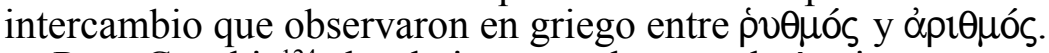

Para Cocchia ${ }^{124}$, los latinos emplearon el término numerus con el sentido de "ritmo", mirándose en el espejo de los griegos, en especial de Aristóteles, en el que aflora la idea aristoxénica de "ritmo" como "ordenación de tiempos", en la que va implícita la idea de "percepción de dicho orden" y de "medida" del mismo. No en vano, dice, los propios latinos harían también un uso amplio del término modus, "medida", para designar conceptos musicales. Se podría pensar, dice, que se tratase de un uso paralelo e independiente que hicieron los latinos de la palabra $n u-$ merus en una acepción técnica especial. Si los griegos hubieran empleado ỏpl $\theta \mu$ ó $\varsigma$, aunque fuera una sola vez, como equivalente

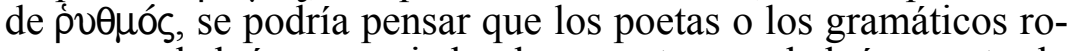
manos se habrían apropiado el concepto y se habrían centrado en uno de los dos términos; algo similar a lo ocurrido con $\gamma \rho \propto \mu-$

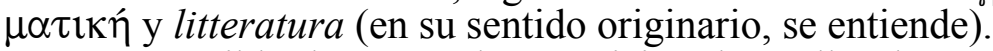

No es posible demostrar la suposición de Müller de que este empleo de numerus fuese una innovación de Ennio bajo el influjo de las doctrinas pitagóricas. Para Cocchia, numerus en su sentido de "armonía" remonta al patrimonio más arcaico de la

$\overline{121} 1891$, p. 16, n. $^{\circ} 1$.

1221879 , p. 2.

${ }^{123}$ Remitía Christ también a Arist., Probl. XIX 38; Platón, Phil. 17d; Ateneo XIV $632 \mathrm{~d}$.

124 1919, pp. 167 ss. 
lengua; es altamente significativo que numerus tenga la misma

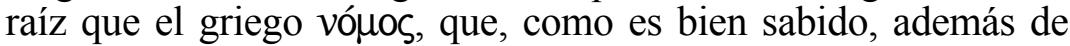
los significados de "distribución" o "ley", tiene el de "armonía". Semejante conexión confirma el concepto de "orden" al que se adscribe esta palabra y clarifica la etimología originaria, que se halla en la base del uso latino del término. En efecto, la equivalencia entre numerus y ṕӪós mal se entiende si no se tiene

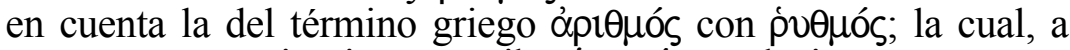

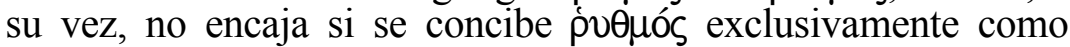
"flujo" o "movimiento" 125 . Es preciso no olvidar su significado primario de "forma", "estructura", tal como lo hemos visto definido en palabras de Jaeger o de Benveniste y tal como sugiere

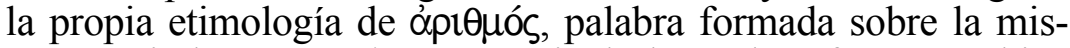
ma raíz indoeuropea *ar-, a partir de la cual se forma también ápuoví $\alpha$ y tantos otros términos relacionados con las ideas de ensamblamiento y estructura, a las cuales hice referencia más arriba.

\section{Las denominaciones latinas: rhythmus/numerus}

El testimonio más antiguo de numerus con el sentido de "ritmo" podría ser, según Castillo, el epitafio de Plauto transmitido por Gelio (I 24). Luego la propia Castillo recoge varios pasajes de Lucrecio, de Catulo y de la Rhetorica ad Herennium que "permiten afirmar que con anterioridad al año 55 a.C. el término numerus se había empleado en latín para expresar nociones de cantidad y orden, y además como designación de la cadencia propia de la danza y referido al ritmo de la versificación poética"126.

La presencia de numerus con este sentido se constata igualmente en Virgilio (ecl. 9, 45 numeros memini, si verba tenerem), en Propercio (III 22,6 Phrygis insanus numerus) o en Ovidio (Am. I 1,27 sex mihi surgat opus numeris, in quinque residat: aquí, como se ve, con el sentido de "unidad de ritmo", "pie métrico").

Cicerón, en su empeño de crear un lenguaje técnico latino, no usará nunca el griego rhythmus, a pesar de que con toda probabilidad dicho término debía de circular normalmente en las escuelas de su época; acude en su lugar a numerus, que, como he resumido en nota anterior, también era ya por entonces de

$\overline{{ }^{125}}$ Es lo que le ocurría a WALTZ 1948.

${ }^{126}$ Castillo 1968, pp. 284 ss. 
uso corriente como tecnicismo para hacer referencia al ritmo. Castillo $^{127}$, sin embargo, recoge con acierto varios pasajes que revelan cómo desde Varrón hasta Mario Victorino se mantiene cierta resistencia al empleo de numerus, que normalmente debe ser explícitamente referido a rhythmus ${ }^{128}$, término éste que lógicamente no necesitaba de explicación ninguna.

Cicerón empleará numerus en estrecha relación o casi en concurrencia con términos como compositio y perfectio ${ }^{129}$ o como forma, que recuerda el griego $\sigma \chi \eta \hat{\mu} \mu \alpha^{130}$, y quadrum ${ }^{131}$. Extiende Cicerón el uso de numerus no sólo a los terrenos de $\rho v \theta \mu o ́ s ~ y$ ápı $\theta \mu o ́ s$, en sus diversos sentidos de estructura y esquemas rít-

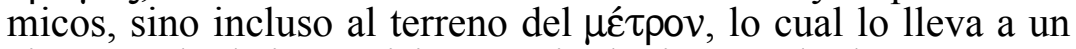
cierto grado de imprecisión terminológica, por lo demás común en sus escritos de retórica, que corren así el riesgo de malentendidos, como ya reconocía Quintiliano, quien además, de acuerdo con su época, liberada ya de aquel rigor de la latinitas ciceroniana, no tenía inconveniente en recurrir al término rhythmus.

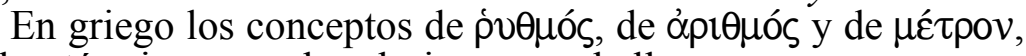
y los términos que los designan, se hallan a veces en concurrencia, de modo que las lindes entre sus respectivos campos se desdibujan en ocasiones, sobre todo dentro del terreno de la expresión lingüística, en prosa o en verso. En latín la delimitación es tanto más difícil como necesaria, pues a la proximidad de los conceptos se añade la peculiaridad terminológica del empleo de numerus.

Numerus con el sentido de "ritmo" en latín tiene, por un lado, que deslindarse de los demás sentidos ("número", "cantidad", "parte de un todo", "rango", "lugar", "orden") con que se emplea. Por otro lado, tiene que entrar en concurrencia con

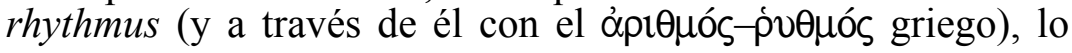

$\overline{127} 1968$, pp. 288 ss.

${ }^{128}$ Rhythmus... latine numerus dicitur: Varro De serm. lat. 87, p. 218 Goetz-Schoell; nam sunt numeri rhythmoe, ut et ipse (Cicero) constituit et secuti eum Vergilius, cum dicit 'numeros memini, si uerba tenerem', et Horatius 'numerisque fertur lege solutis': Quint. IX 4,53; rhythmum qui latine numerus vocatur: Diom. GLK I 513,1 s.; latine numerus dicitur, ut Vergilius 'numeros memini... ': Mar. Vict. GLK VI 41,25 .

${ }^{129}$ Or. 181, 182, 228.

${ }^{130}$ De or. III 199.

${ }^{131}$ Or. 208, 233. 


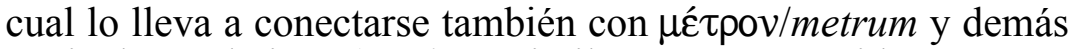
equivalentes latinos (modus y similares, en un sentido; versus y similares, en otro). Todo ello, sin embargo, sobrepasa los límites del presente trabajo.

\section{Bibliografía utilizada}

ABERCROMBIE, D.: 1965: “A phoneticien's view of verse structure", en Studies in Phonetics \& Linguistics. London.

-1967: Elements of general phonetics. Edinburgh.

AILI, H.: 1979: The Prose Rhythm of Sallust and Livy. Stud. Lat. Stockholmiensia 24: Stockholm.

ALLEN, W.S.: 1965: Vox latina. Cambridge.

-1969: "The latin accent: a restatement". Journal of Linguistics, 1969, 5, pp. 136 ss.

-1973: Accent and Rhythm. Cambridge.

BALBÍN, R. de: 1968: Sistema de rítmica castellana, 1968 (2a).

BENVENISTE, E.: 1951: "La notion de 'rythme' dans son expression linguistique”. Journal de Psychologie, 1951 (=Problémes de linguistique générale, Paris, 1966, pp. 327-335).

CAESAR, J.: 1861: Die Grundzüge der griechischen Rhythmik. Marburg.

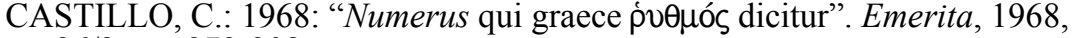
36/2, pp. 279-308.

COCCHIA, E.: 1919: "Numerus e carmen nell'antica poesia latina". Riv. indo-greco-italica, 1919, 3, pp. 1-10.

COHEN, J.: 1966: Structure du langage poétique. Paris.

CHATMAN, S.: 1965: A Theory of Meter. The Hague.

CHRIST, W.: 1879: Metrik der Griechen und Römer. Leipzig, 1879.

DE GROOT, A.W.: 1930: "La métrique générale et le rythme". BSL, 1930, 30, pp. 202-232.

-1932: "Der Rhythmus”. Neophilologus, 1932, 17, pp. 81-100, 177-197, 241-265.

-1933: "Le mètre et le rythme du vers". Journal de psychologie, 1933, 30, pp. 326-332.

-1968: "Phonetics in its relation to aesthetics", en Malmberg 1968, pp. 523-549.

DREXLER, H.: 1941: "Rhythmus und Metrum". Glotta, 1941, 29, pp. 1-28.

FRISK, H.: 1960: Griechisches Etymologisches Wörterbuch. Heidelberg.

FRITZ, K.v.: 1938: Philosophie und sprachlicher Ausdruck bei Demokrit, Plato und Aristoteles. New York-London.

FRY, D.B.: 1958: "Experiments in the perception of stress". Language and Speech, 1958, 1, pp. 126 ss.

-1964: "The function of the syllable". Zphon, 1964, 17, pp. 215 ss. 
GARCÍA CALVO, A.: 1975: El ritmo del lenguaje. Barcelona. - 1979: Del lenguaje. Madrid.

GARCÍA HERNÁNDEZ, B. (ed.), 1998: Estudios de lingüística latina. Madrid.

GARVIN, L.: 1964: A Prague School Reader on Esthetics, Literary Structure and Style. Georgetown.

GOODELL, T.D.: 1901: Chapters on Greek Metre. New York-London.

GRAF, R.: 1891: Rhythmus und Metrum. Marburg.

HARDING, D.W.: 1976: Words into rhythm. English speech rhythm in verse and prose. Cambridge.

HERESCU, N.I.: 1960: La poésie latine. Paris.

HERNÁNDEZ VISTA, V.H.: 1972: "Ritmo, metro y sentido". Prohemio, 1972, III/1, pp. 93-107.

JAEGER, W.: 1933: Paideia. Die Formung der griechischen Menschen, trad. J. Xirau-W. Roces. México.

LAVER, J.: 1994: Principles of Phonetics. Cambridge.

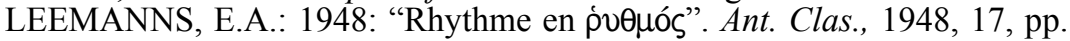
403 ss.

LEHISTE, I.: 1970: Suprasegmentals. Cambridge, Mass.

LUQUE MORENO, J.: 1984: "Sistema y realización en la métrica. Bases antiguas de una doctrina moderna". Emerita, 1984, 52/1, pp. 33-50.

-1987: Scriptores Latini de re metrica. Vol I Presentación. Granada.

-1994: Arsis, thesis, ictus: las marcas del ritmo en la música y en la métrica antiguas. Granada.

-1995: De pedibus, de metris. La medida del ritmo en la música y en la poesía antigua. Granada.

-1998: "Vox (sonus) - sermo - carmen - cantus - versus - oratio", en García Hernández 1998, pp. 971-985.

-2001: "Numerus: la articulación rítmica del lenguaje" (Ponencia presentada al X Congreso Español de Estudios Clásicos, Alcalá de Henares, Septiembre 1999). Actas del X Congreso Español de Estudios Clásicos, vol. II. Madrid, 2001, pp. 493-527.

-2001b: "Metrica y grammatica", en J. Dangel (ed.), Le poète architecte. Arts métriques et art poétique latins. Louvain-Paris, 2001, pp. 13-50.

-2002: "Forma y medida en los versos greco-latinos: la génesis del sistema de niveles". Emerita, 2002, LXXII-2, pp. 231-256.

-2006: Accentus ( $\pi \rho 0 \sigma \omega \delta i ́ \alpha)$ : el canto del lenguaje. Representación de los prosodemas en la escritura alfabética. Granada.

-2006b: Puntos y comas. La grafia de la articulación del habla. Granada.

MALMBERG, B.: 1968: Manual of Phonetics. Amsterdam.

MARINER, S.: 1971: "Carácter convencional del ritmo", en Coloquios de historia y estructura de la obra literaria. Madrid, 1971, pp. 89-96 (= 1999, pp. 427-434).

-1999: Latín e Hispania antigua. Scripta minora. Madrid.

MAROUZEAU, J.: 1949: Quelques aspects de la formation du latin littéraire. Paris. 
MUKAROVSKY, J.: 1931: "La Phonologie et la Poétique". Travaux Cercl. Ling. Prag., 1931, 4, pp. 278-288.

-1964: "The Connection between the Prosodic Line and Word Order in Czech Verse", en Garvin 1964, pp. 113 ss.

PIKE, K.L., 1946: The Intonation of American English. Ann Arbor, Michigan. -1948: Tone Languages. Ann Arbor, Michigan.

PRIMMER, A.: 1968: Cicero numerosus. Wien.

RODRÍGUEZ ADRADOS, F.: 1969: Lingüistica estructural. Madrid.

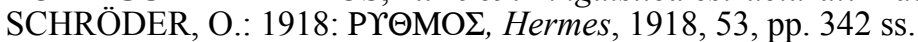

SEYDEL, G.: 1914: "Rhythmik", en Pauly-Wisowa, RE s.v.

SONNENSCHEIN, E.A.: 1925: What is Rhythm?. Oxford.

STETSON, R.H.: 1951: Motor Phonetics. Amsterdam.

VANDVIK, E.: 1937: Rhythmus und Metrum. Iktus und Akzent. Oslo.

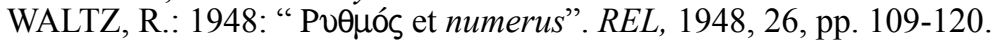

WARREN, H.C.: 1934: Dictionary of Psychology. Boston.

WELLEK, R.-WARREN, A.: 1953: Teoría literaria, trad. J. Ma Gimeno. Madrid.

WESTPHAL, R., 1867: Westphal, R.-Rossbach, A., Griechische Rhythmik und Harmonik nebst der Geschichte der musischen Disziplinen $\left(2^{\mathrm{a}}\right)$. Lepizig.

-1885: Theorie der musischen Künsten der Hellenen: I Griechische Rhythmik. Leipzig.

-1887: Theorie der musischen Künsten der Hellenen: III,1 (col. H.Gleditsch): Allgemeine Theorie der griechische Metrik. Leipzig, 1887.

WOLF, E.: 1955: "Zur Etymologie von p’0 1 uós und seiner Bedeutung in der älteren griechischen Literatur". W. St., 1955, 68, pp. 99 ss. 